\title{
Challenges of applying monophyly in the phylogenetic shallows: taxonomic reappraisal of the Dactylorhiza maculata group
}

\section{Richard M. Bateman ${ }^{1}$ (D)}

Summary. The first study of the taxonomically critical European orchid genus Dactylorhiza to use next-generation DNA sequencing generated the statistically best-supported reconstruction of its phylogeny to date. However, the two competing topologies obtained within the monophyletic Section Maculatae differed radically in the placement of the D. maculata s.s.-D. foliosa clade. Both topologies showed D. foliosa to be nested deeply within D. maculata s.s., and suggested that D. saccifera s.l. is paraphyletic, D. saccifera s.s. from south-eastern Europe and Asia Minor diverging before D. gervasiana from south-central Europe (a taxon typically viewed as a subspecies of $D$. saccifera or, more often, ignored completely). The poorly-sampled but character-rich morphometric comparison presented here suggests that $D$. saccifera s.s. and D. gervasiana cannot be distinguished with confidence using morphological characters and that, if $D$. gervasiana is accepted as a species, it is effectively cryptic. The diploid $D$. foliosa is accepted as an island endemic species, despite rendering paraphyletic the autotetraploid D. maculata s.s.; all other named taxa within the D. maculata s.s. clade are considered infraspecific. Dactylorhiza fuchsii is indisputably a bona fide species rather than a subspecies but it does not merit becoming the basis of a taxonomic section separate from D. maculata s.s. The strongly contrasting degrees of molecular vs morphological disparity reported here are representative of a more general trend evident in groups that have experienced comparatively recent speciation, as is the need to recognise occasional paraphyletic species when circumscribing species by integrating genotypic and phenotypic data categories. Explicit taxonomic criteria combined with a comparative, monographic approach are needed to achieve consistency of ranking. Disproving hypotheses of species status is judged a criminally underrated activity, actually being as important to outcomes as much-vaunted species "discovery".

Key Words. Cladistic classification, cryptic species, Dactylorhiza foliosa, Dactylorhiza gervasiana, Dactylorhiza islandica, Dactylorhiza saccifera, monophyly, morphometrics, multivariate analysis, phylogeny, RAD-seq, speciation, species circumscription.

\section{Introduction}

Brandrud et al. (2020) published a well-received and thoroughly sampled phylogenetic study of the genus Dactylorhiza (Necker ex Nevski) Soó that relied upon a comparatively recent 'next-generation' genetic analytical technique termed RAD-seq (restriction siteassociated sequencing). This genome fragmentation technique yields large numbers of variable DNA bases from throughout the three plant genomes (nuclear, plastid, mitochondrial) and is particularly suited for the study of plants that are only subtly distinct genetically (e.g. Baird et al. 2008; Rubin et al. 2012; Paun et al. 2016). As RAD-seq had already been applied to the genus Ophrys (Bateman et al. 2018a), Gymnadenia s.1. (Brandrud et al. 2019) and the Epipactis helleborine aggregate (Sramkó et al. 2019), Dactylorhiza was the obvious next European orchid genus to benefit from this welcome technical advance. The taxonomy of Ophrys is rendered problematic primarily by the consequences of its high-risk pseudocopulatory pollination, that of the E. helleborine aggregate by its tendency to produce near-obligately self-pollinating species and subspecies, and that of Gymnadenia and Dactylorhiza by their tendency toward frequent ploidy change, generating both allopolyploids and autopolyploids.

In the case of the derived clade within Dactylorhiza that includes the D. maculata and D. incarnata groups, allopolyploids have long been known to originate through repeated hybridisation events between similar parental lineages within these two species groups, each event being combined with genome doubling to generate a novel lineage whose ability to reproduce with either parent is consequently considerably reduced. Each novel polyploid lineage can justifiably be viewed as an equally novel species (e.g. Bateman 2012b), though an alternative 'Scandinavian' philosophy argues that all allopolyploid lineages originating between the same pair of parental species should be regarded as conspecific despite their demonstrable

Accepted for publication 24 May 2021. Published online 4 November 2021

1 Jodrell Laboratory, Royal Botanic Gardens Kew, Richmond, Surrey, TW9 3DS, UK. e-mail: r.bateman@kew.org 
polyphyly (cf. Pedersen 1998; Hedrén 2005; Kühn et al. 2019). Unfortunately, the majority of the recent taxonomic treatments of the genus have - as is commonplace in the discipline of taxonomy offered no conceptual justification of any kind for the decisions taken by the authors.

Given the evident long-term scientific interest in the genus (e.g. Vermeulen 1947), it is unsurprising that the Dactylorhiza maculata-incarnata clade has become a model system for the study of allopolyploidy (e.g. Hedrén et al. 2007, 2008; Paun et al. 2010, 2011; Balao et al. 2016, 2017), or that next-generation sequencing techniques would therefore be brought to bear on this taxonomically troublesome group. Understandably, when next-generation techniques were eventually applied to Dactylorhiza, the resulting RAD-seq study by Brandrud et al. (2020) set aside taxonomic implications in order to focus on the evolutionary interpretation of their results, placing particular emphasis on providing a framework within which allopoly ploidisation processes and their downstream consequences could be better understood.

Here, I critically appraise current molecular phylogenetic knowledge of the group, focusing on the Brandrud et al. (2020) RAD-seq trees, before reviewing in detail the implications of these trees for the systematics of just one narrowly-delimited clade within the genus Dactylorhiza that has for centuries proven exceptionally intractable from a taxonomic viewpoint - the D. maculata group (reviewed by Stahlberg 2007, 2009; Stahlberg \& Hedrén 2008). I implement in situ morphometric analyses (sensu Bateman 2011, 2021) that are based on severely limited data but nonetheless explore the relative similarities of the best-known taxa within the clade and test perhaps the most surprising results in the molecular topologies of Brandrud et al. (2020): (1) the apparent diphyly of D. saccifera s.l. (Fig. $1 \mathrm{~A}-\mathrm{E}$ ), and (2) the nesting of the island-endemic diploid D. foliosa (Fig. 1F) within the consequently paraphyletic autotetraploid D. maculata s.s. I also explore infraspecific taxonomy within D. saccifera s.l. and D. maculata s.s. (Fig. 2). I then review the ongoing taxonomic and evolutionary problems posed by the D. maculata clade overall, reluctantly concluding that integrating present molecular and morphological evidence requires a polythetic classification that recognises five species. In reaching this pragmatic conclusion I found myself reluctantly obliged to treat the criteria for cladistic classification that I have previously repeatedly prescribed (Bateman 2009, 2012a, 2021) as strong guidelines rather than as unbreakable rules.

\section{Background: Summary of the RAD-seq study}

Brandrud et al. (2020) compiled a RAD-seq data matrix derived from 225 plants: 207 dactylorchids (representing 28 putative species) plus 18 diploid outgroups. The outgroups could be divided into an 'inner outgroup' of Gymnadenia (including Nigritella) and 'outer outgroups' of Galearis (represented by an east Asiatic species that formerly constituted the monotypic genus Neolindleya), Pseudorchis and Platanthera (cf. Bateman et al. 2003). The filtered matrix of 25,354 variable DNA bases yielded multiple topologies for a comprehensive spectrum of diploid and autotetraploid species (exemplified by the present Fig. 3, based on Figs 3 and S1 of Brandrud et al. 2020). The new topologies differ significantly from any of the several topologies previously published for the genus Dactylorhiza, irrespective of whether they were based on morphological (Bateman et al. 2018b) or molecular data (e.g. Bateman et al. 2003, 2018b; Devos et al. 2006a; Pillon et al. 2006, 2007; Inda et al. 2012; reviewed in detail by Bateman et al. 2018b).

Despite the vast numbers of characters made available by RAD-seq, at least four crucial inferred relationships still received comparatively poor statistical support (i.e. bootstrap values of less than $85 \%$ ). The enigma of whether the earliest-divergent species is Dactylorhiza viridis or D. iberica, explored in detail by Bateman \& Rudall (2018) and Bateman et al. (2018b), was not convincingly solved. The placement of $D$. viridis as diverging earlier than $D$. iberica received only $73 \%$ support in the preferred likelihood tree of Brandrud et al. (2020), and the equivalent coalescence tree marginally (and improbably, when viewed in the context of all other available data) favoured divergence of $D$. iberica slightly later than that of D. sambucina. Dactylorhiza sambucina has itself long been a source of instability in trees of the genus, and in the RAD-seq likelihood trees it was placed as sister to the combined incarnata-umbrosa-euxina and fuchsiimaculata-aristata clades with only $50 \%$ support. This result pushed the incarnata group into a more derived position within the tree than was found in any previous molecular study (reviewed by Bateman et al. 2018b). Among the diploid marsh-orchids, D. euxina was shown to be sister to $D$. umbrosa (incorporating the former D. osmanica) plus D. incarnata, all three species being strongly supported as monophyletic. The position of the Siberian-Alaskan D. aristata as sister to the D. maculata group has molecular precedence only in the nrITS + rpl tree of Pillon et al. (2006) and is still in need of explanation, given its vast geographic disjunction from all Dactylorhiza species other than the circumpolar D. viridis.

The most surprising ambiguities in the Brandrud et al. (2020) topology - and the focus of this article are relationships inferred within the "spotted-orchid" clade epitomised by D. maculata s.l. (Figs 1, 2). The autotetraploid D. maculata has the diploid Madeiran endemic D. foliosa embedded deeply within it. Also, in the tree of Brandrud et al. (2020) that included all 

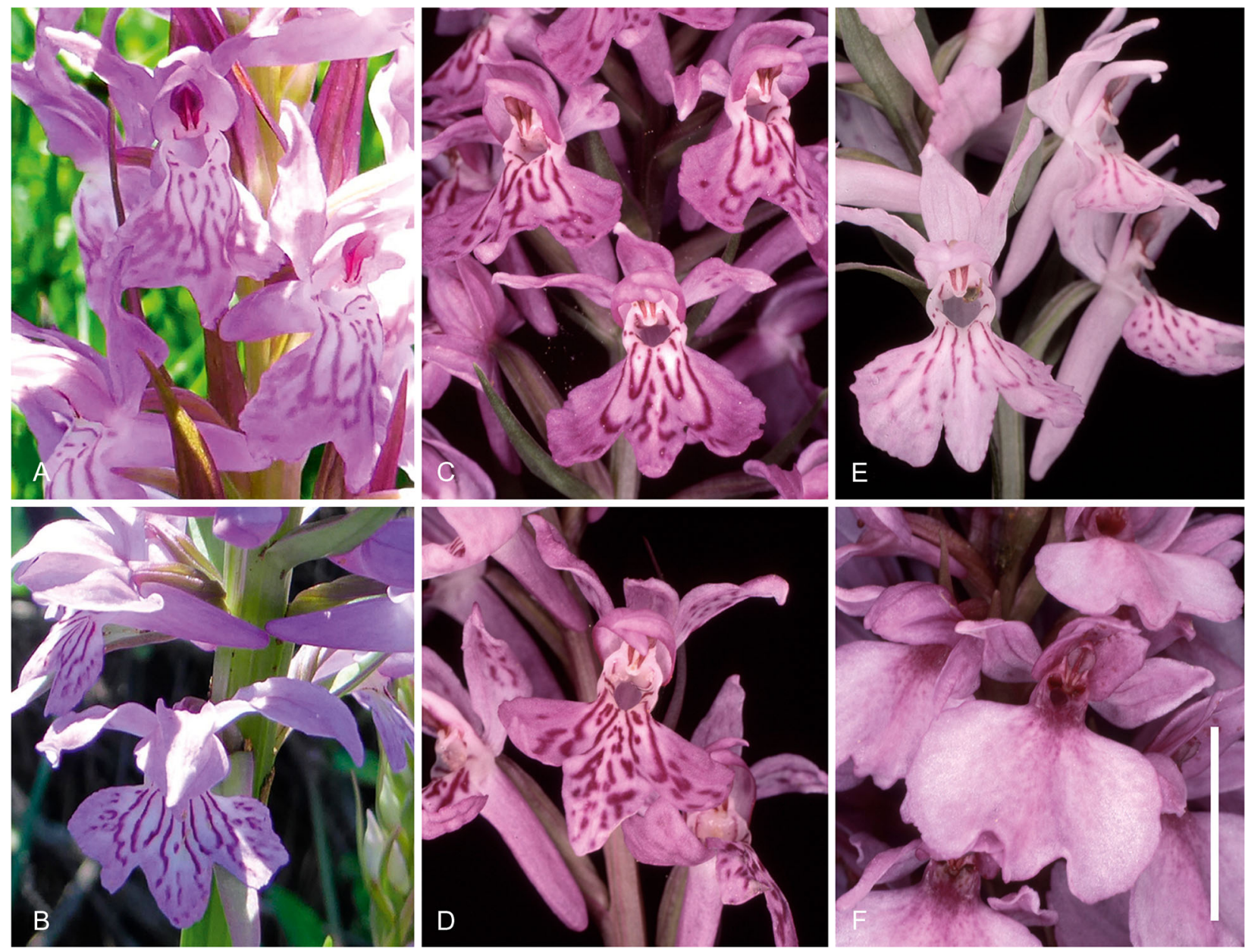

Fig. 1. Representative examples of A, B Dactylorhiza saccifera s.S.; C - E D. gervasiana; F D. foliosa. Localities: A Monastiri, Epirus, Greece; B Metsovo, Epirus, Greece; C Castelpoggio, Apuan Alps; D San Andrea, Elba; E Fonte Napoleone, Elba; F Royal Botanic Garden Edinburgh (collection B), ex Madeira. Scale bar for all images $=1 \mathrm{~cm}$. PHOTOS: A, B P. RUDALL, C - F R. BATEMAN.

analysed samples (Fig. 3A), this combined maculatafoliosa clade is sister to a clearly monophyletic, genetically cohesive $D$. fuchsii. Dactylorhiza saccifera s.l. (Fig. 1) is resolved as sister to the remaining members of the D. maculata group. Although this relationship gained poor statistical support, it is a topology for Section Maculatae that is consistent with the results of some previous studies based largely or wholly on nuclear ribosomal ITS sequences (Bateman et al. 2003; Pillon et al. 2006, 2007).

Remarkably, Brandrud et al. (2020) found that omitting from the analysis a few accessions of Dactylorhiza maculata collected in eastern Europe was sufficient to alter inferred relationships such that the remaining western European samples of D. maculata (with D. foliosa still embedded deeply within them) were instead perceived as sister-group to the remaining taxa of the $D$. maculata group, thereby leaving $D$. saccifera pro parte as sister to $D$. fuchsii only. This relationship was more consistent with perceived morphological similarity and was eventually chosen by
Brandrud et al. (2020, their fig. 3 = the present Fig. 3B) as their preferred phylogenetic hypothesis. Among several previous molecular studies, only the ITS + ETSbased tree of Devos et al. (2006a) - comparatively weakly sampled - had yielded this topology for Section Maculatae.

Even more surprisingly, in both the all-taxon and reduced-taxon topologies of Brandrud et al. (2020), Dactylorhiza saccifera s.l. was not resolved as monophyletic but rather as diphyletic. Samples from east and west of the Adriatic Sea formed separate clades, the eastern saccifera group evolutionarily diverging before the western saccifera group, albeit again with poor statistical support (51\% in Fig. 3A, $85 \%$ in Fig. 3B). Sampling was limited but apparently showed reliable geographic separation of the two groups. The eastern clade contained four samples representing northcentral Greece, Bulgaria, Georgia and north-central Turkey - the two latter being attributed in the comprehensive monograph of Eccarius (2016) to the so-called D. saccifera subsp. amblyoloba (Eccarius 2016) 


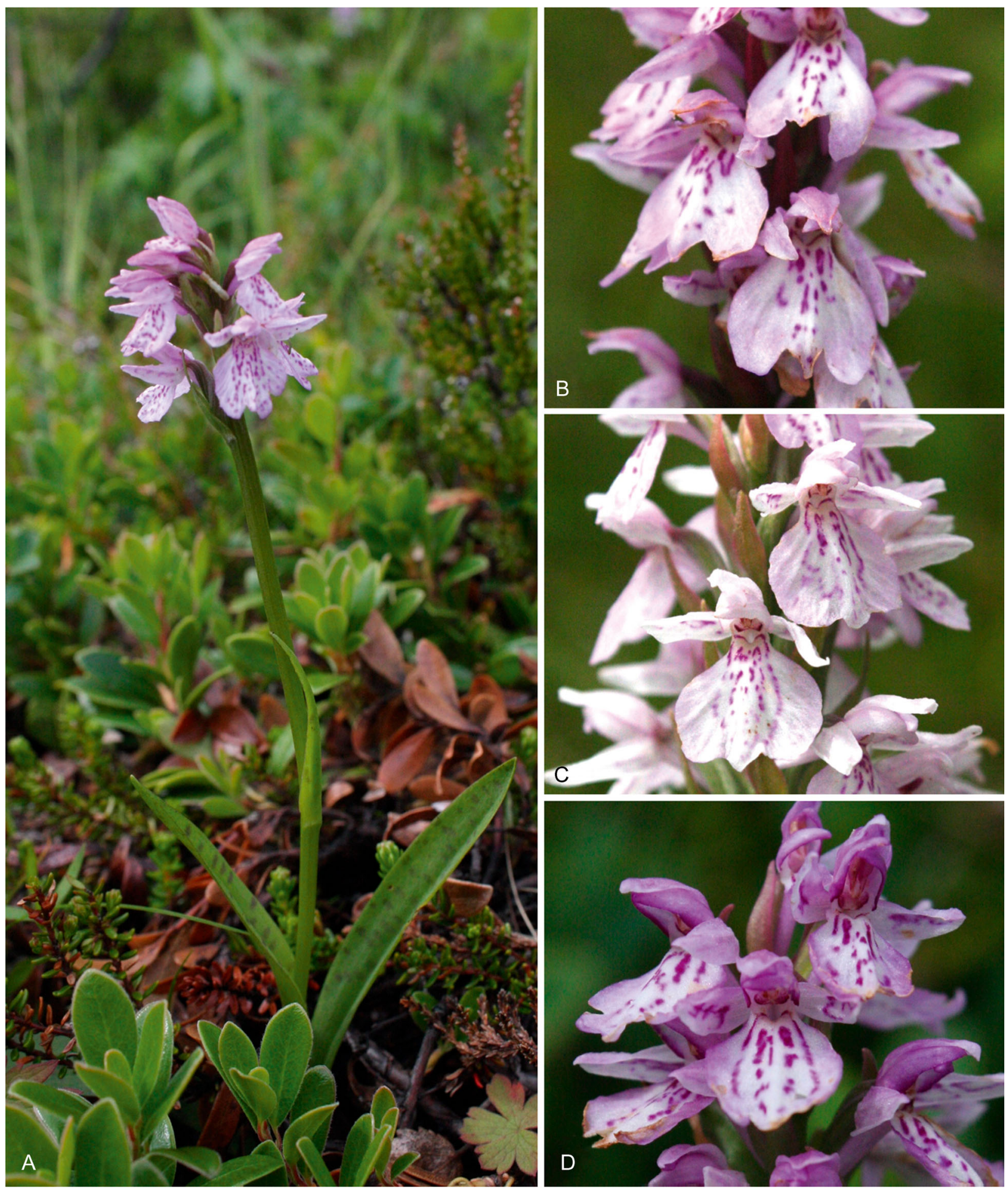

Fig. 2. A - D Examples of the Icelandic endemic Dactylorhiza maculata "subsp. islandica" from the morphometrically studied population at Thingvillir. PHOTOS: R. BATEMAN.

and subsp. bithynica (Kreutz 1998) respectively. The western clade consisted of three samples: two from central Italy plus one from Corsica, all therefore attributable to $D$. saccifera subsp. gervasiana according to Eccarius (2016).
Taxonomically, the eastern clade constitutes Dactylorhiza saccifera s.s.; that is, D. saccifera (Brongn.) Soó (1962), a binomial based on Orchis saccifera Brongn. (Brongniart 1832). There is a formal name already available at both species and subspecies rank 


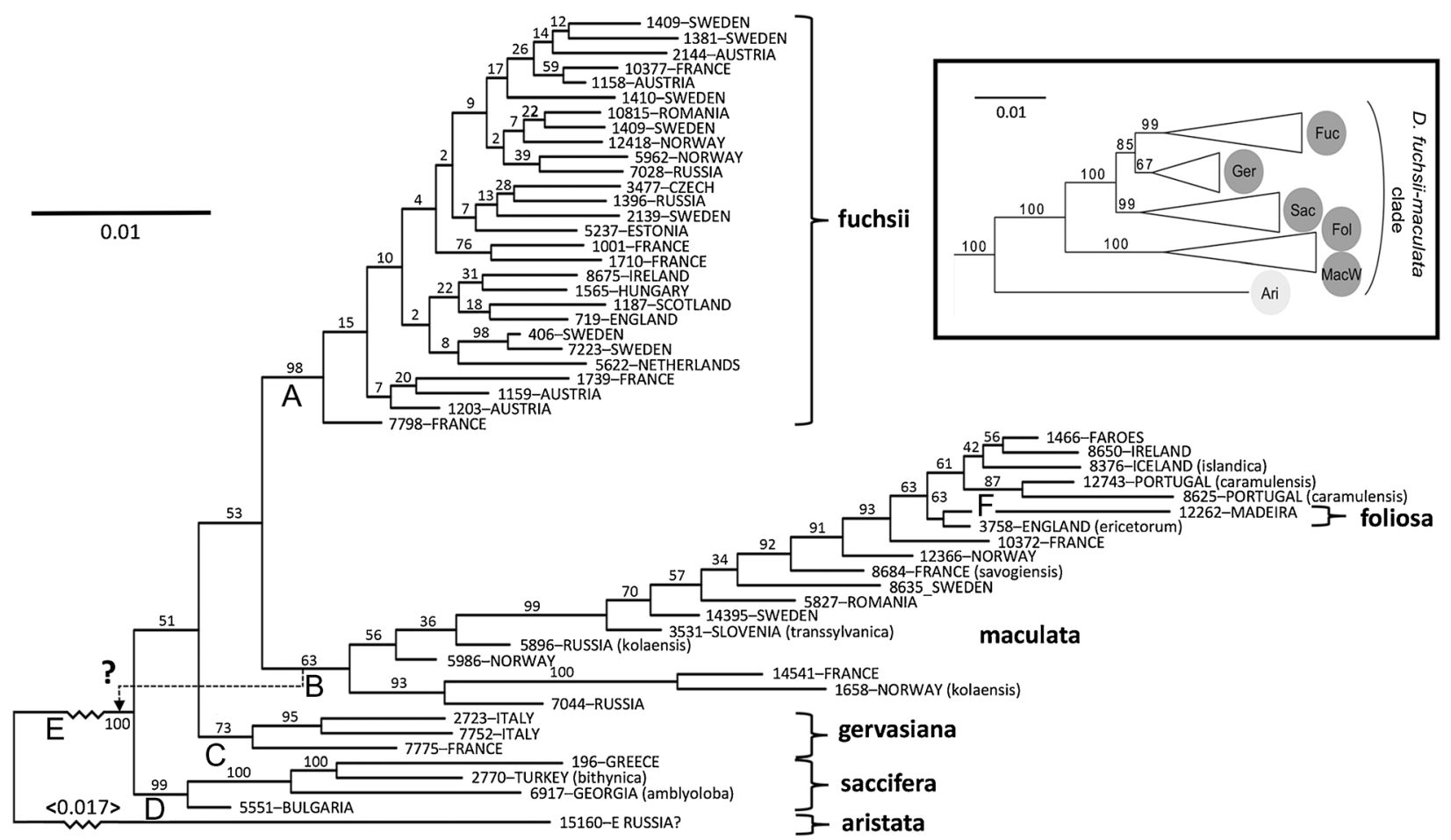

Fig. 3. Molecular phylogenies of Dactylorhiza section Maculatae, derived from taxonomically broader trees constructed via RAxML from 19,305 nuclear SNPs generated through RAD-seq. A Tree including several specimens of eastern European D. maculata s.S., heavily redrafted from Supplementary Fig. 1 of Brandrud et al. (2020), with taxonomic assignments revised and geographic origins of samples added. Figures above the branches are bootstrap values based on 1,000 rapid replicates; letters $A-D$ represent four putatively monophyletic groups within Section Maculatae. B Portion of the preferred topology of Brandrud et al. (2020, their fig. 8); D. maculata s.s. is placed lower in the tree as a consequence of excluding the eastern European specimens.

that encompasses the western clade: D. gervasiana (Tod.) H.Baumann \& Künkele (1981), also known as D. saccifera subsp. gervasiana (H.Baumann \& Künkele) Kreutz (2004) but rooted nomenclaturally in the far older Orchis gervasiana Tod. (Todaro 1842). This comparatively obscure taxon has been thrown into sharp focus by the unexpected hypotheses of relationship derived from the RAD-seq data of Brandrud et al. (2020); it therefore merits further examination.

\section{Materials and Methods}

The limited morphometric data used in this preliminary study represent 12 populations or aggregate 'metapopulations' (Table 1), six of which were published previously as part of a much larger study of British and Irish spotted-orchids by Bateman \& Denholm (1989). The remaining six populations were measured in Continental Europe (five populations) or in the Royal Botanic Garden Edinburgh (one 'metapopulation') over a 35-year period, initially being viewed as stand-alone data-sets intended only for eventual comparison with British populations of Dactylorhiza fuchsii and D. maculata.

In total, 52 of the 53 morphometric characters recorded for the present study were described in detail by Bateman \& Denholm (1985) and so will not be repeated here. Only one additional character was introduced, recording the fact that Dactylorhiza foliosa deviates from the remaining species in possessing lateral petals that are usually somewhat spreading, thereby contrasting with the arrangement evident in most dactylorchids where the lateral petals are overlapped by the median sepal to form a "connivent" hood that shelters the column. Two characters proved to be invariant within the spectrum of taxa analysed: labellar sinuses were uniformly present, whereas markings on the underside of the leaves were uniformly absent. The remaining 51 characters describe the stem and inflorescence (5), leaves (11), leaf markings (6), bracts and ovary (7), labellum (13), spur (4) and sepals (4). They can alternatively be categorised as metric (21), meristic (3), multistatescalar (22) and bistate (4). Flower colour was recorded by matching the colour of the lower half of the labellum to the closest colour block(s) of the Royal Horticultural Society Colour Chart, facilitating subsequent conversion to three quantified colour variables long recognised by the Commission Internationale de I'Eclairage.

Data for individual plants were summarised in an Excel v15.4 spreadsheet. Mean values, sample standard 
Table 1. Details of populations sampled for the present study. Asterisked populations were among the 43 spotted-orchid populations studied by Bateman \& Denholm (1989).

\begin{tabular}{|c|c|c|c|c|c|}
\hline Taxon & Locality & Habitat & Altitude (m a.s.l.) & $\begin{array}{l}\text { Date } \\
\text { measured }\end{array}$ & $\begin{array}{l}\text { No. plants } \\
\text { measured }\end{array}$ \\
\hline \multirow[t]{2}{*}{ fuchsii } & ODDY Hill, Chiltern Hills, SE England* & Dry chalk downland & 170 & June 1982 & 10 \\
\hline & Near AXAMS, Innsbruck, W Austria & Scrubby roadside banks & c. 1000 & July 1997 & 10 \\
\hline \multirow[t]{2}{*}{ gervasiana } & Four sites, Elba island, TUSCANY, Italy & Shady woods and ditches & $160-380$ & May 2006 & 7 \\
\hline & $\begin{array}{l}\text { Three sites, Apuan Mountains, } \\
\text { TUSCANY, Italy }\end{array}$ & Shady woods-open scrub & $250-1000$ & May 2006 & 3 \\
\hline saccifera s.s. & $\begin{array}{l}\text { Kleidonia, near Konitsa, EPIRUS, NW } \\
\text { Greece }\end{array}$ & $\begin{array}{l}\text { D e n s e ly wood e d } \\
\text { floodplain }\end{array}$ & 410 & June 2017 & 5 \\
\hline \multirow[t]{2}{*}{ foliosa } & Madeiran endemic $[\mathrm{A}]$ & $\begin{array}{l}\text { RBG Edinburgh } \\
\text { (cultivated) }\end{array}$ & $700-1500$ & June 1995 & 3 \\
\hline & Madeiran endemic [B] & $\begin{array}{l}\text { RBG Edinburgh } \\
\text { (cultivated clone) }\end{array}$ & $700-1500$ & June 1995 & 5 \\
\hline maculata ?s.s. & $\begin{array}{l}\text { THURSLEY Common, Surrey, SC } \\
\text { England* }\end{array}$ & Sphagnum bog & 55 & June 1983 & 10 \\
\hline \multirow[t]{3}{*}{$\begin{array}{l}\text { maculata } \\
\text { ericetorum }\end{array}$} & $\begin{array}{l}\text { KYNANCE Cove, Lizard, Cornwall, SW } \\
\text { England* }\end{array}$ & Heathland & 70 & June 1984 & 10 \\
\hline & $\begin{array}{l}\text { GLENCAIRN meadow, NE Aviemore, } \\
\text { C Scotland* }\end{array}$ & Hill pasture & 220 & July 1983 & 10 \\
\hline & $\begin{array}{l}\text { LAWERS Burn, SW Kenmore, C } \\
\text { Scotland* }\end{array}$ & Boggy flush & 360 & June 1983 & 12 \\
\hline \multirow{2}{*}{$\begin{array}{l}\text { maculata } \\
\text { rhoumensis } \\
\text { islandica }\end{array}$} & $\begin{array}{l}\text { Upper KILMORY Glen, Rum, Inner } \\
\text { Hebrides, WC Scotland* }\end{array}$ & Sphagnum bog & 50 & July 1983 & 10 \\
\hline & $\begin{array}{l}\text { N park visitor centre, THINGVILLIR, } \\
\text { SW Iceland }\end{array}$ & $\begin{array}{l}\text { Heathland and open } \\
\text { scrub }\end{array}$ & 195 & July 2014 & 10 \\
\hline
\end{tabular}

deviations and coefficients of variation were then calculated for the four aggregated populations of, respectively, Dactylorhiza fuchsii, D. maculata, D. foliosa, $D$. saccifera s.s. and D. gervasiana. Univariate analyses were summarised and presented using Deltagraph v7.1 (SPSS/Red Rock software).

The initial Section-wide matrix of 63 plants $\times 53$ characters (total 3339 cells) contained 56 (1.7\%) missing values: of these, 16 represented failed bractcell measurements for some members of the English fuchsii population plus all members of the saccifera population, and a further 24 represented the majority of the vegetative characters that proved unscorable for one of the Elban gervasiana plants. A second matrix, employing the same range of characters, was compiled to explore in greater detail variation within populations of Dactylorhiza maculata s.s. growing in exposed habitats near the Atlantic coastline of northern Europe. This aspect of the study compared five populations from the British Isles plus one from Iceland. The resulting matrix of 42 plants $\times 53$ characters (total 2226 cells) contained just nine $(<0.1 \%)$ missing values.

In total, six characters were excluded from each of the multivariate analyses: five leaf-marking characters were omitted to avoid over-weighting this single feature (retaining only the percentage of upper leaf surface marked), and the presence of a basal leaf/sheath was omitted as it proved to be too strongly influenced by premature, habitat-related decay.
Data for the remaining 45 characters were analysed by multivariate methods using Genstat v14 (Payne et al. 2011). They were employed to compute a symmetrical matrix that quantified the similarities of pairs of data for individual plants using the Gower Similarity Coefficient (Gower 1971) on unweighted data sets scaled to unit variance. This similarity measure is comparatively effective when presented with a matrix of heterogeneous characters that includes missing values (Gower \& Legendre 1986; Bateman 2021). The resulting matrix was in turn used to construct a dendrogram and a minimum spanning tree (Gower \& Ross 1969) and subsequently to calculate principal coordinates (Gower 1966, 1985) - compound vectors that incorporate positively or negatively correlated characters that are most variable and therefore potentially diagnostic. Principal coordinates are especially effective for simultaneously analysing heterogeneous suites of morphological characters and can comfortably accommodate missing values. As such, they have proven invaluable for assessing relationships among orchid species and populations throughout the last three decades (reviewed by Bateman 2001, 2011) and are the crux of the present morphometric study.

Four rounds of multivariate data analysis were performed. The first analysis involved the complete matrix of data available for Section Maculatae. The second analysis omitted the Dactylorhiza maculatafoliosa clade in order to better explore the relationship between $D$. fuchsii and $D$. saccifera s.l. The third analysis also omitted D. fuchsii and so was confined to 
comparing D. gervasiana with $D$. saccifera s.s., seeking morphological characters that might usefully distinguish between the two taxa differentiated on molecular grounds by Brandrud et al. (2020). The fourth and final analysis utilised the alternative matrix designed to compare populations of D. maculata s.s. from exposed habitats, an analysis that included three named variants each of ambiguous taxonomic status (ericetorum, rhoumensis, islandica: Table 1, Fig. 2).

\section{Results}

\section{Overview of the maculata clade}

The strong (23\%) first principal coordinate of the analysis of the four taxa in the maculata clade that are most commonly recognised as being full species yielded a clear discontinuity separating the Madeiran island endemic Dactylorhiza foliosa from the remaining taxa (Fig. 4). Characters primarily responsible for this discontinuity were the large labellum ("lip"), absence of leaf markings, and failure of the lateral petals to form a hood with the median sepal in D. foliosa. Subsidiary characters contributing to the morphological distinctiveness of $D$. foliosa included the larger number of both expanded and bract-like leaves, its yellower green leaf colour, its paler pink flower colour, and its subdued labellum markings - low in contrast and dominated by dashes rather than loops.

The somewhat weaker $(17 \%)$ second coordinate depicts the remaining taxa as a continuum, Dactylorhiza maculata s.s. being linked to an aggregate of D. saccifera and the English D. fuchsii population via the alpine Austrian population of D. fuchsii. In contrast, the two populations of D. foliosa analysed here appear moderately distinct from each other. Several heterogeneous characters contribute to this axis (Fig. 4), no single character being truly diagnostic of any of the taxa. The strongest contributing characters are the less angular marginal bract cells and paler pink flower colour of D. foliosa and D. maculata (moderate differences in labellum reflectivity also separating the foliosa A and B populations). The third and fourth axes were weak and achieved no taxonomic distinctions.

Ten individual metric characters and two shape indices of potential diagnostic value at species level are further explored in Figs 5 - 10. Labella of Dactylorhiza foliosa are far larger than those of the other taxa analysed (Fig. 1F, Fig. 5, inset); otherwise, there is a gradation of increased size from English fuchsii to Austrian fuchsii (particularly variable) and English maculata, then Scottish maculata, saccifera and finally gervasiana. The labellum roundness index is not discriminatory, whereas the shape index sensu Heslop-Harrison (1951) achieves its objective in distinguishing D. maculata (and also D. foliosa) from the remaining species, the optimal cut-off value approximating 1.22 (Fig. 6). Dactylorhiza saccifera is capable of achieving especially high values for this index. Labellar spurs of $D$. foliosa are particularly short, and those of D. maculata are particularly narrow (Fig. 7). The Alpine population of $D$. fuchsii bridges the gap to D. saccifera s.l. - a taxon that features spurs that are substantially longer and especially broader than those of the remaining species.

The plot of labellum reflectivity vs bract length (Fig. 8) demonstrates the unusually pale labella of British populations of both Dactylorhiza fuchsii and D. maculata. Dactylorhiza foliosa, D. gervasiana and D. saccifera s.s. have somewhat longer bracts than D. fuchsii and D. maculata. Comparison of leaf length vs leaf width (Fig. 9) shows that a length : width ratio of approximately $1: 6$ distinguishes the narrow-leaved D. maculata from both D. fuchsii and the especially broad-leaved $D$. foliosa, but this ratio is bridged by D. saccifera s.l. Intriguingly, species-level regressions reveal contrasting allometric trajectories; the leaves of $D$. foliosa broaden rapidly as length increases, whereas those of D. saccifera s.l. remain a near-constant width with increased length (Fig. 9). Finally, the plot of inflorescence length vs number of flowers (Fig. 10) shows the Scottish population of D. maculata to have particularly dense inflorescences whereas $D$. saccifera s.l. tends toward lax inflorescences (fewer than four flowers per $\mathrm{cm}$ ).

\section{saccifera s.l. vs fuchsii}

The principal coordinates analysis that encompassed only fuchsii and saccifera s.l. distinguished these two taxa but failed to separate plants of Dactylorhiza gervasiana from those of D. saccifera s.s. (cf. Fig. 1A B vs C - E, Fig. 11). The first coordinate successfully separated D. saccifera s.l. from the English population of $D$. fuchsii, but what would otherwise have been a morphological discontinuity proved to be occupied by the population of D. fuchsii from the Austrian Alps (Axams). That first axis is again relatively strong, accounting for $23 \%$ of the total variance and being influenced by 18 of 49 variable morphometric characters that collectively reflect the colours and sizes of both the plants and flowers. The second axis is considerably weaker (13\%) and is determined primarily by the proportion of the labellum occupied by markings (they were restricted to the central region of the labellum of the Axams population of D. fuchsii); this axis partially separates that Alpine population from the remainder. The third and fourth axes are trivial and so are not illustrated here.

Labellum dimensions reliably distinguish the English population of Dactylorhiza fuchsii from D. saccifera s.l., but the Alpine population is intermediate and overlaps with both of the other clusters (Fig. 5). Most 


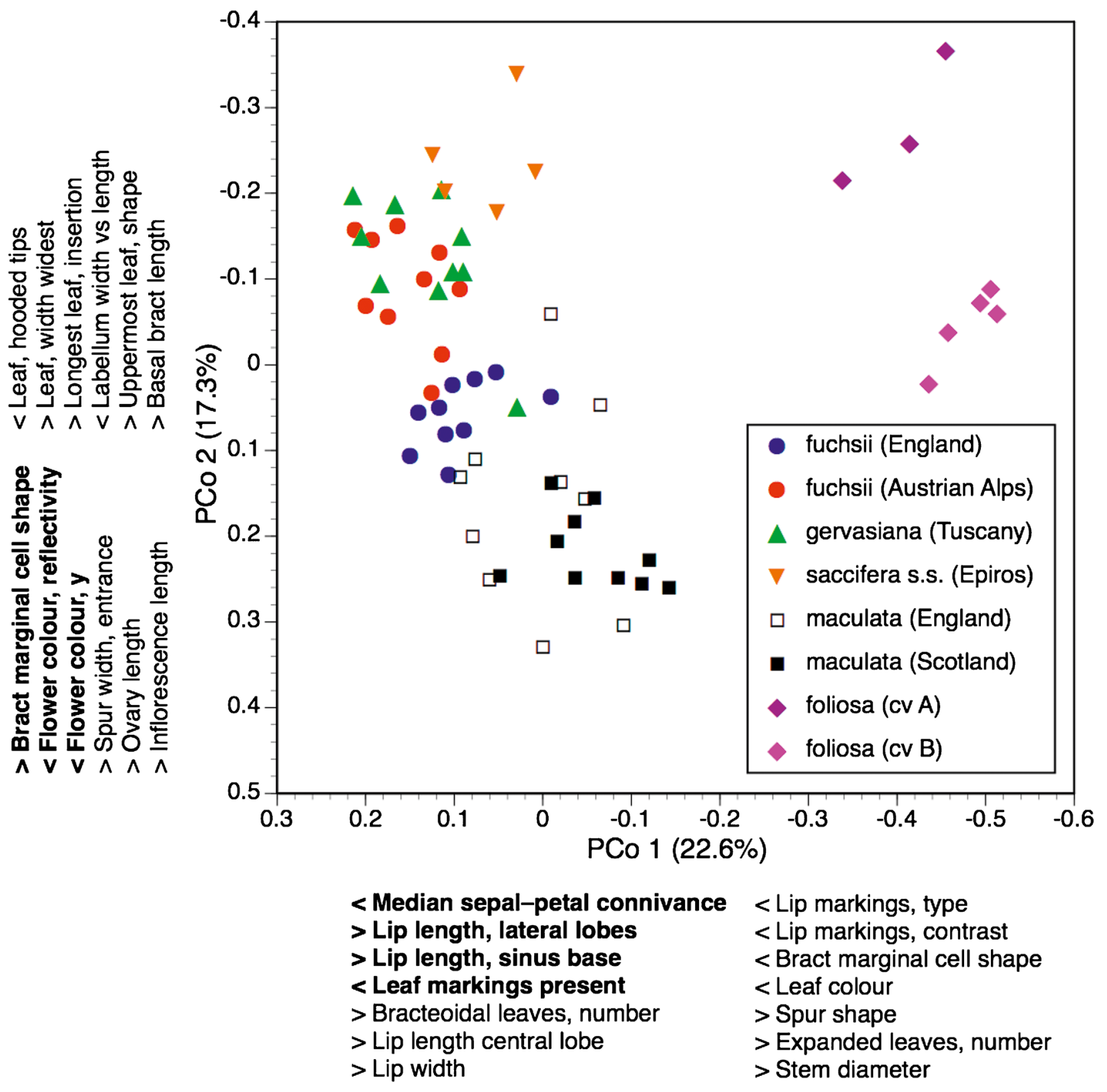

Fig. 4. Plot of principal coordinates 1 vs 2 for 45 morphometric characters and 64 individuals of Dactylorhiza section Maculatae. Characters contributing to the coordinates are listed in order of decreasing importance; dominant variables are shown in boldface.

plants of D. saccifera have labella larger than $8 \mathrm{~mm} \times 11$ $\mathrm{mm}$, and tend to have larger width : length ratios than D. fuchsii (Fig. 6). A similar distribution of plants is evident in the plot of spur measurements (Fig. 7); most spurs of D. saccifera s.l. exceed $8 \mathrm{~mm}$ in length and $2.5 \mathrm{~mm}$ in diameter. Spurs of D. saccifera s.l. are also reliably straight, whereas those of the majority of D. fuchsii plants are at least slightly down-curved. Leaf length offers only partial separation of D. saccifera s.l. from the typically smaller-leafed $D$. fuchsii; the optimal threshold value between the two species approximates $100 \mathrm{~mm}$ (Fig. 9). However, basal bract length appears more diagnostic than leaf length; most D. saccifera s.l. exceed $18 \mathrm{~mm}$ whereas all $D$. fuchsii fall between $7 \mathrm{~mm}$ and $18 \mathrm{~mm}$ (Fig. 8). A similarly useful (though far from reliable) species-level threshold is evident in the floral bracts, approximating a length of about $12 \mathrm{~mm}$ in D. saccifera s.l. In addition, D. saccifera s.l. tends to have fewer plants that bear solid loop markings on their lips and leaves that are a slightly darker, bluer green than those of $D$. fuchsii.

It is noteworthy that none of Figs $5-10$ offers much hope of distinguishing morphometrically between Dactylorhiza gervasiana and D. saccifera s.s. (ironically, it is considerably easier to distinguish between the two analysed populations of D. fuchsii). 


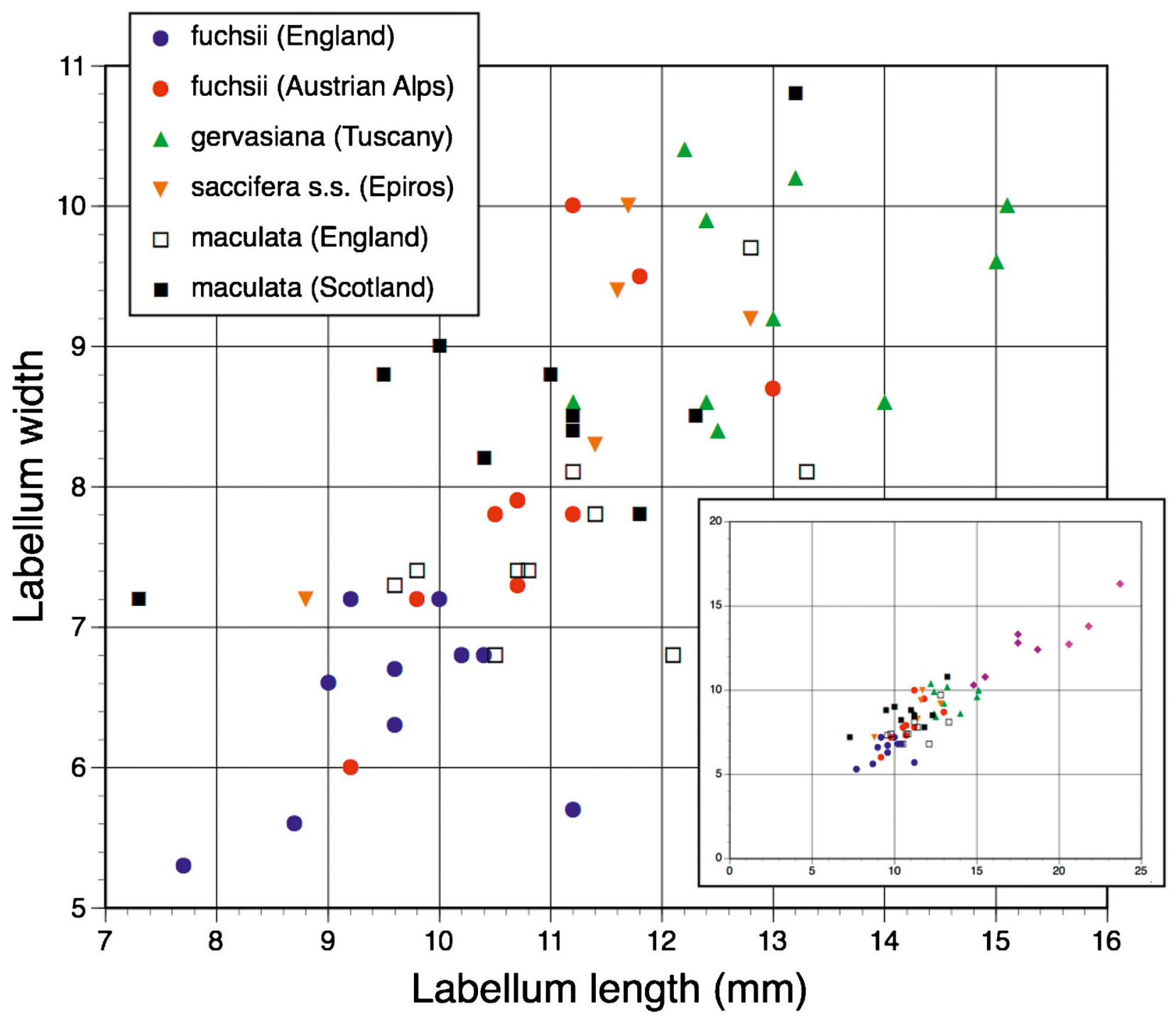

Fig. 5. Bivariate scattergram of labellum length to apex of central lobe vs labellum maximum width for individuals of Section Maculatae (inset) and the Section minus Dactylorhiza foliosa (main diagram). Dactylorhiza foliosa is represented in the topright of the inset by purple diamonds.

Compared with the English downland population of D. fuchsii, the alpine Austrian population tended to have larger labella $(>7.5 \times 10.5 \mathrm{~mm}$ : Fig. 5) and longer spurs (> $7 \mathrm{~mm}$ : Fig. 7). It included some comparatively anthocyanin-rich plants that had purple-stained bracts (also in some cases bearing sporadic small purple-brown spots) and that exhibited some annular markings on the leaves in addition to the usual solid markings. The English plants selected here had on average one extra expanded leaf and one additional bract-like leaf, but they appeared to be incapable of reaching the maximum plant size achieved by the larger among the Austrian fuchsii plants. The majority of the English plants had paler labella that typically reflected more than $50 \%$ of the incident light (Fig. 8), and they bore pink-purple markings that extended across a larger proportion of the labellum.

gervasiana vs saccifera s.s.

In the hope of detecting meaningful morphometric separation of Dactylorhiza gervasiana from D. saccifera s.s., we conducted a separate principal coordinates analysis that involved only these two taxa (Fig. 12); these plots were also relabelled to distinguish between plants of D. gervasiana from Elba (Fig. 1D, E) and those occurring at higher altitudes in the Apuan Mountains of mainland Tuscany (Fig. 1C). It is (just) possible to draw a diagonal line on the plot of the first two coordinates that would separate gervasiana from saccifera s.s., but the overall impression given is that of 


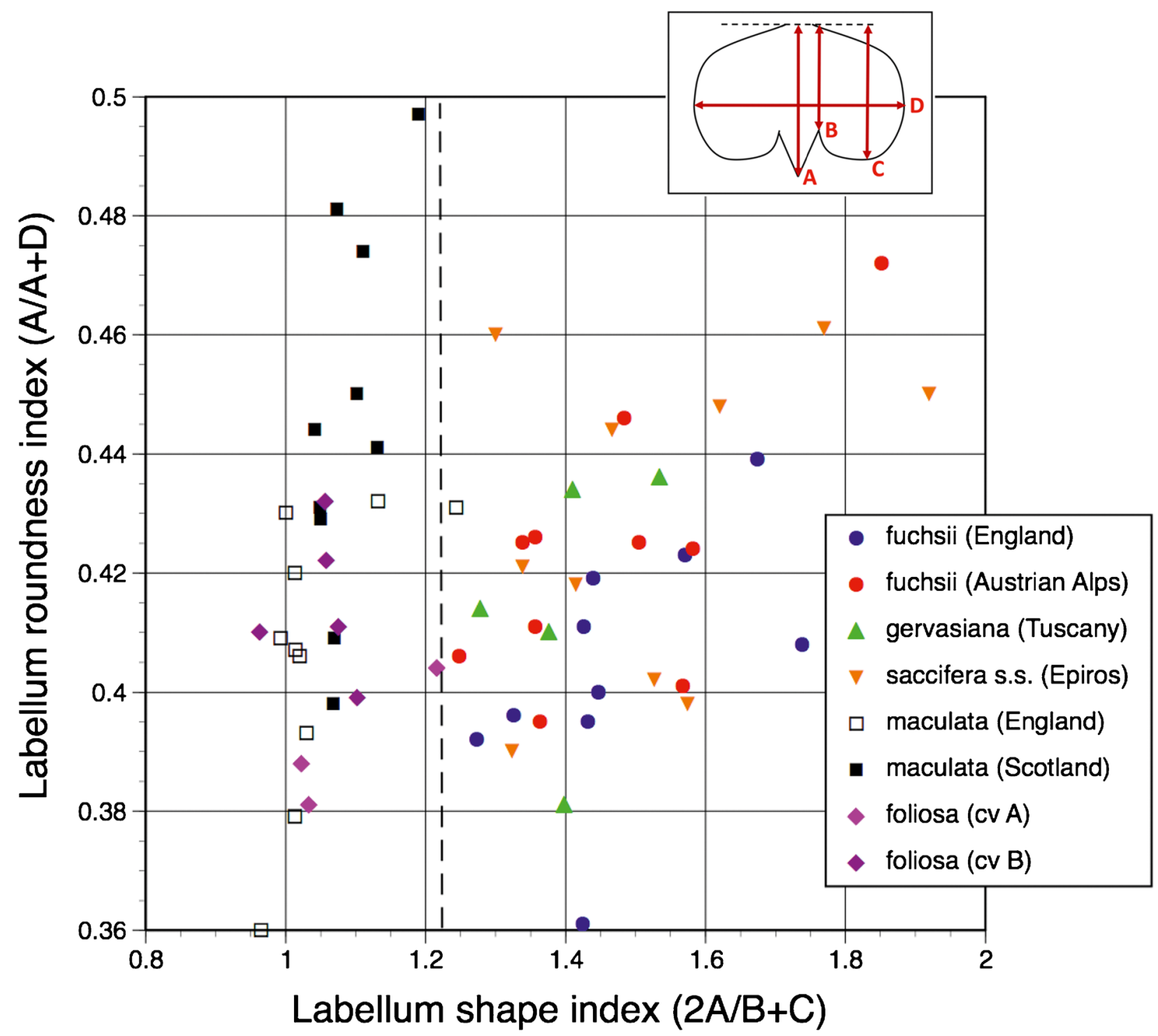

Fig. 6. Bivariate scattergram of the labellum shape index of Helsop-Harrison (1951: $2 A /[B+C])$ vs the labellum roundness index of Bateman \& Denholm (1983: AV[A+D]) for individuals of Section Maculatae. The inset illustrates dimensions A - D.

a single cluster rather than of two or more clusters of potential taxonomic significance. And predictably, the third and fourth coordinates proved to lack any diagnostic value.

Although the first two coordinates appear reasonably strong in percentage terms (totalling 35\%: Fig. 12), these plots actually summarise comparatively little variation. More crucially, there is little overall structure to the available variation. Characters contributing to the first two axes are poorly correlated, and some of the strongest contributors actually apply to only a minority of the plants. For example, only $20 \%$ of the gervasiana plants bore a minority of annular rather than uniformly solid leaf markings (first coordinate) and less than 50\% exhibited dilute anthocyanin pigments on the upper regions of their stems and on their bracts (second coordinate).
More can actually be learned in this context by plotting individual characters in pairwise comparisons. The labella of gervasiana tend to be longer, half of the sampled plants exceeding $13 \mathrm{~mm}$ (Fig. 5), and their average spur width is slightly greater (Fig. 7), refuting previous suggestions that it was significantly less. Fig. 9 shows that although leaf length does not distinguish between the two taxa, leaf width offers $100 \%$ separation of our (admittedly very small) samples; all plants of gervasiana had a maximum leaf width of $25 \mathrm{~mm}$ but all plants of saccifera s.s. exceeded this value. This plot also suggests greater consistency of the sizes of plants and their component organs within gervasiana compared with saccifera s.s., which appears to be capable of generating a minority of unusually large plants. This impression is enhanced by the plot of inflorescence length against flower number (Fig. 10), which shows 


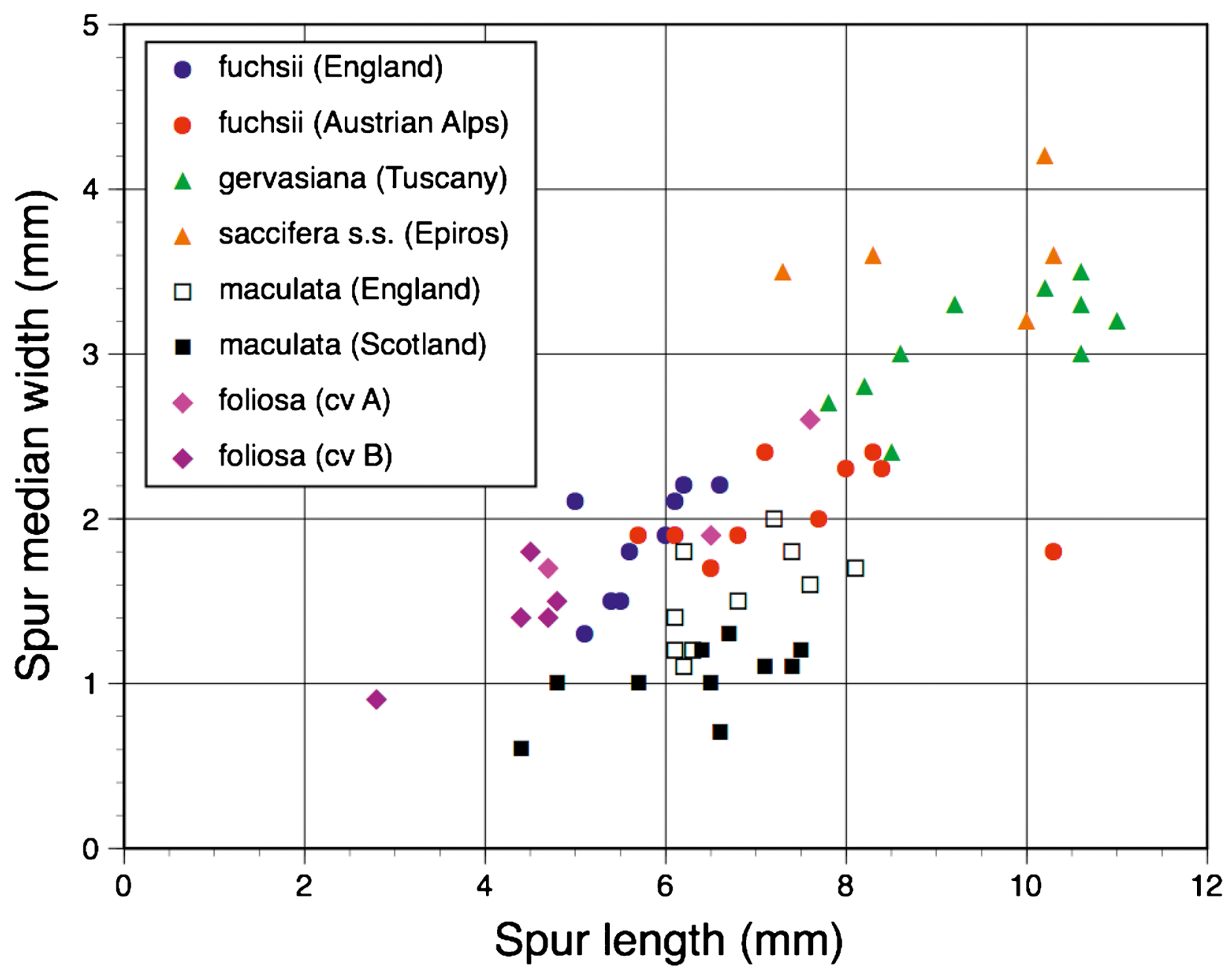

Fig. 7. Bivariate scattergram of spur length vs spur median width for individuals of Section Maculatae.

two of the five sampled saccifera s.s. plants to be especially floriferous, whereas flower number in gervasiana plants was surprisingly consistent at about 18. And a minority of plants of saccifera s.s. had purplespotted bracts. When considering the implications of these observations, it is important to recall the small sample sizes per taxon included in these analyses.

\section{Within Dactylorhiza maculata s.s.}

The three British populations in this analysis represented Dactylorhiza maculata ericetorum from a coastal peninsula in Southwest England (Kynance) and a mountainside in central Scotland (Lawers), together with putative $D$. maculata rhoumensis from the coast of the island of Rum in the Inner Hebrides (Kilmory). These populations from comparatively exposed habitats were selected primarily for comparison with Thingvillir (Fig. 2), a population of the segregate of D. maculata characteristic of Iceland, islandica, which is regarded as a full species by some authors (Averyanov 1990; Delforge 2016) but as a subspecies of D. maculata by the majority (e.g. Senghas 1968; Soó 1980; Kreutz 2004; Baumann et al. 2006; Eccarius 2016).

In stark contrast with the clear separation of Dactylorhiza folios $a$ on the first principal coordinate of Fig. 4, the first coordinate in the present analysis fails to distinguish among any of the four populations, instead being dictated largely by a negative correlation between plant size (increasing to the right) and the amount of anthocyanin staining on vegetative organs (increasing to the left). In other words, smaller plants of D. maculata inexplicably tend to exhibit more anthocyanin staining (Fig. 13A). The second coordinate offers partial separation of the Thingvillir and Kilmory populations from the remainder, but only on the basis of slight differences in leaf shape. Unusually, it is the plot of the third and fourth coordinates (Fig. 13B) that generates greater — though nonetheless only partial - separation of the four populations; Lawers is partially separated along PCo3 through a diverse mixture of weakly discriminatory characters, and Kynance is partially separated on PCo4 through its marginally larger mean sizes of flower and bract. But interestingly, it is the Thingvillir population of "islandica" — separated by 


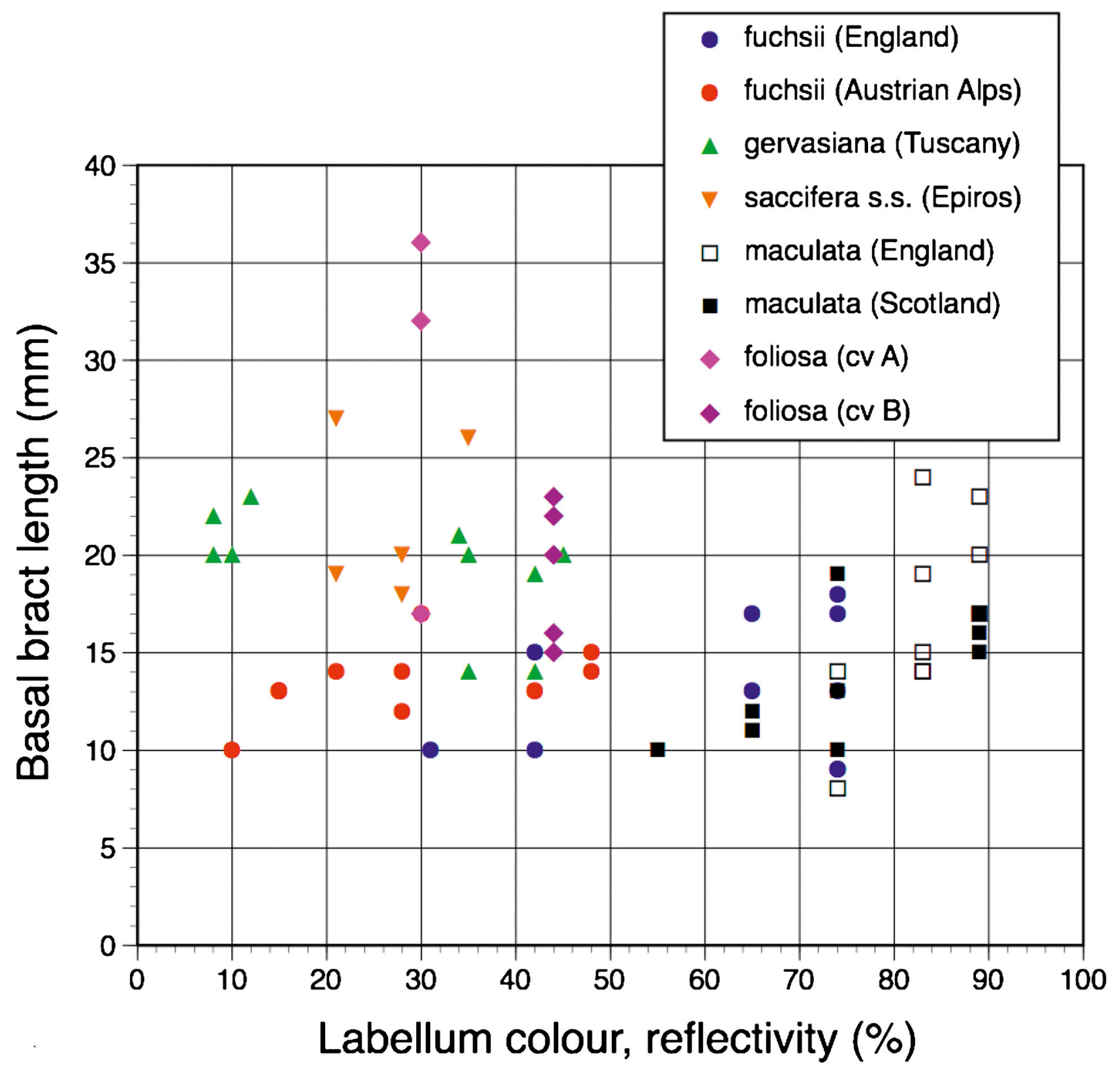

Fig. 8. Bivariate scattergram of length of basal bract vs percentage reflectivity of labellum (representing the depth of the pink anthocyanin pigments) for individuals of Section Maculatae (the reflectivity of pure white is c. $89 \%$ ).

some authorities as a full species endemic to Iceland - that resides in the centre of the plot and thus presents a "median morphology" for the group, rather than showing the clear disparity from $D$. maculata s.s. that would reasonably be expected of a separate species or subspecies.

\section{Discussion}

Given that I was prompted to write this paper primarily by the molecular phylogenies recently published by Brandrud et al. (2020), the obvious topic to begin this Discussion is a critical reappraisal of their results, for which, as a junior author, I take partial responsibility.

\section{Critique of the RAD-seq results}

Is the RAD-seq topology obtained for the genus Dactylorhiza credible?

There is no doubt that the number of variable molecular characters generated by Brandrud et al. (2020) via their RAD-seq study $(25,354)$ far exceeds those obtained in any previous, candidate-gene based studies of Dactylorhiza (summarised by Bateman et al. $2018 \mathrm{~b})$; viewed in that context, the paper is an impressive advance. Nonetheless, there is a numerical contrast between the numbers of plants analysed for D. fuchsii (28) and D. maculata (18) vs D. saccifera (4), D. gervasiana (3) and D. foliosa (1) (Fig. 3). Confidence 


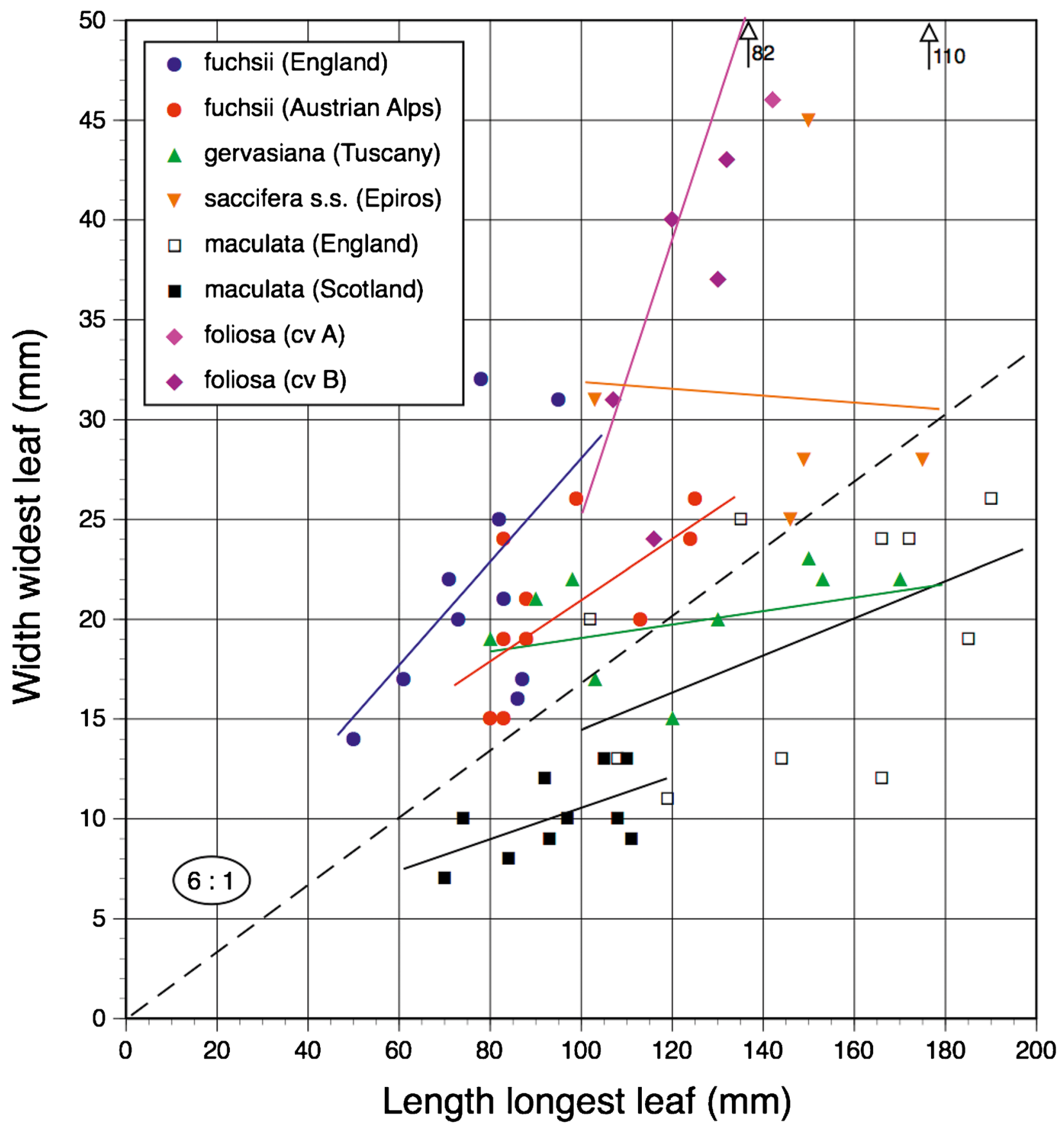

Fig. 9. Bivariate scattergram of leaf length vs leaf maximum width for individuals of Section Maculatae. Regression lines are shown for each population. Two individuals of Dactylorhiza foliosa strain B have exceptionally broad leaves of $82 \mathrm{~mm}$ and $110 \mathrm{~mm}$ respectively.

in the rigour of that topology is further enhanced by the fact that Brandrud et al. (2020) obtained similar topologies using two radically contrasting mathematical methods of tree building: maximum likelihood and coalescence. Admittedly, in the absence of D. aristata and the autotetraploid D. maculata s.s., coalescence methods yielded improbable topologies in which $D$. sambucina was tentatively hypothesised to arise immediately before $D$. iberica. On the other hand, simply removing several easterly plants of $D$. maculata from the analysis was sufficient to alter the phylogenetic position of the maculata s.s.-foliosa clade (cf. Fig. $3 \mathrm{~A}$ vs $3 \mathrm{~B}$ ). And confidence in both the all-sample and reduced-sample topologies of Brandrud et al. (2020) might be further diminished by the realisation that neither topology matches those generated in any previous, taxonomically well-sampled, DNA-based study (cf. Bateman et al. 2003, 2018b; Devos et al. 


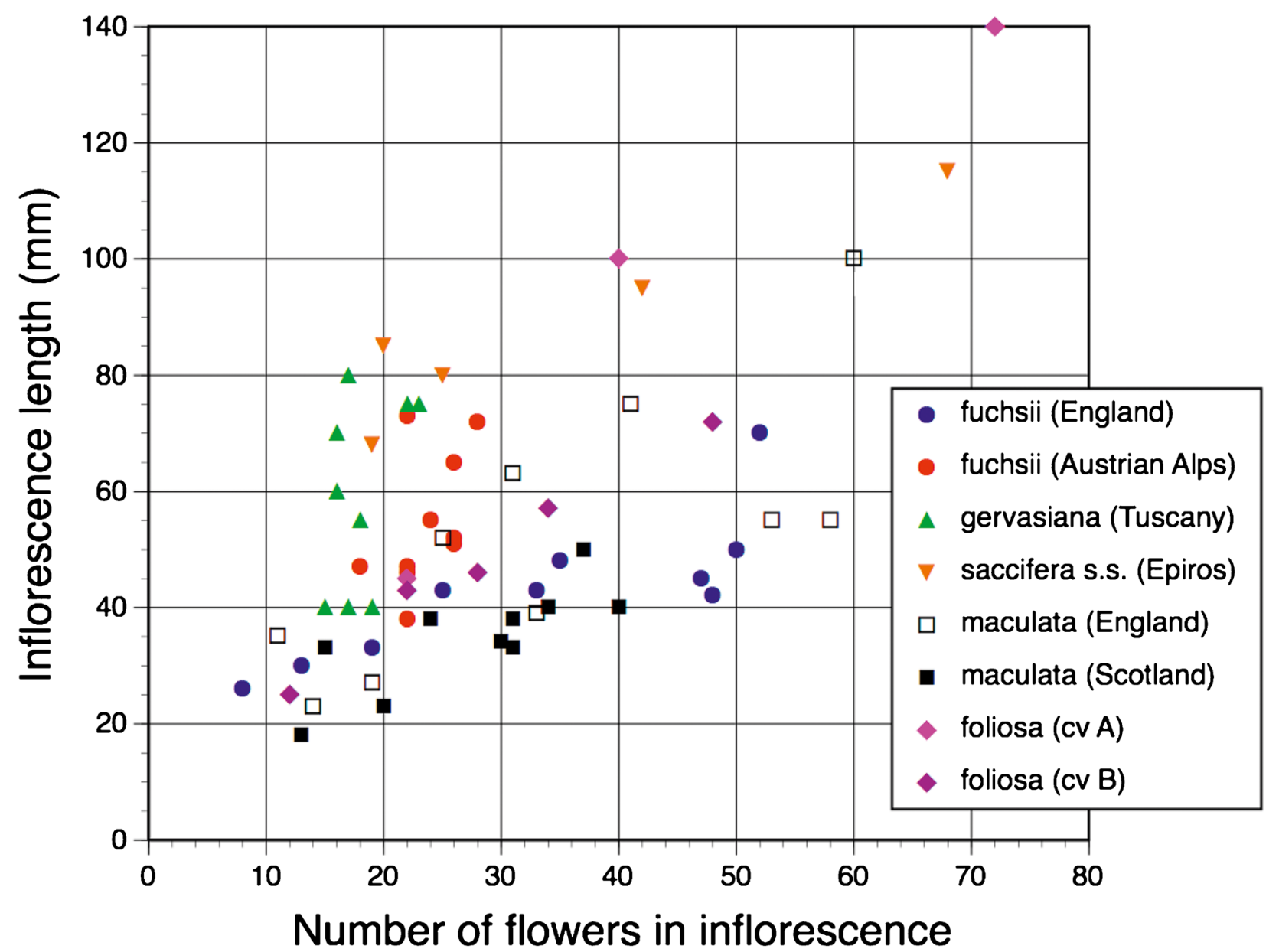

Fig. 10. Bivariate scattergram of inflorescence length vs number of flowers in the inflorescence for individuals of Section Maculatae.

2006a; Pillon et al. 2006, 2007; Inda et al. 2012), nor those generated through morphological cladistic analyses (topics reviewed in detail by Bateman et al. 2018b).

Certainly, there is a price to pay for acquiring vastly expanded data matrices through NGS methods, in the form of both the bewildering complexity of decisions taken during the data filtration processes and the topological instability that often becomes evident when altering the threshold of percentage of missing values that is considered acceptable by the data analyst (e.g. Cozzolino et al. 2020; Bateman 2021). More traditional matrices constructed from one to few genes are of course far poorer in meaningful data but, in compensation, the matrices are usually more-or-less complete, thus simplifying data analysis. A somewhat Faustian trade-off is an inevitable consequence of gaprich matrices, because lowering the proportion of missing values in a RAD-seq matrix in order to reduce topological ambiguity also greatly reduces the number of characters that remain available for tree building. Also noteworthy is the fact that the least stable aspects of previous molecular trees — the relationship be- tween Dactylorhiza viridis and D. iberica, the relationship between the $D$. sambucina group and the $D$. incarnata group - remain comparatively poorly statistically supported in the Brandrud et al. (2020) analyses (Fig. $3)$, despite the vastly increased numbers of characters that contribute to the relevant branches of their trees.

\section{Is the RAD-seq topology obtained for the maculata group credible?}

The uncertainties in the Brandrud et al. (2020) trees that are the focus of the present paper relate to the Dactylorhiza maculata group (the clade consisting of every non-allotetraploid taxon that diverged later than the northeast Asian-Alaskan endemic D. aristata in Fig. 3). Their trees accord with those of most previous molecular studies in reporting strongly supported monophyly of the entire D. maculata group and in the inclusion within the autotetraploid D. maculata s.s. of the diploid $D$. foliosa, endemic to Madeira.

The topology for the Dactylorhiza maculata group shown in Fig. 3A, which places D. maculata s.s. (plus D. foliosa) as sister to D. fuchsii, is consistent with previous studies based on nuclear ribosomal ITS 


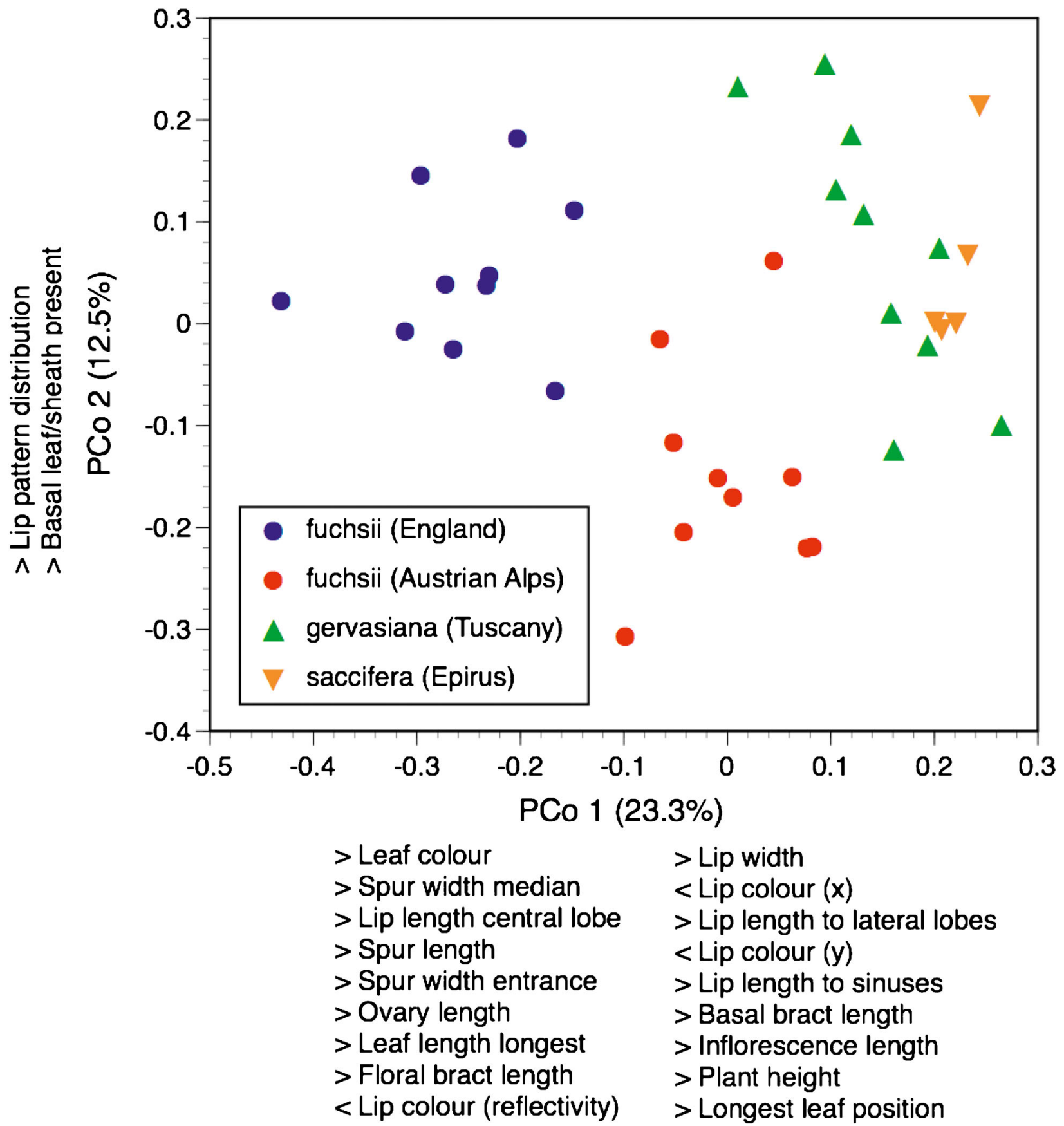

Fig. 11. Plot of principal coordinates 1 vs 2 for 45 morphometric characters and 35 individuals of Dactylorhiza fuchsii, D. saccifera and $D$. gervasiana only. Characters contributing to the coordinates are listed in order of decreasing importance.

sequences (Bateman et al. 2003; Pillon et al. 2006, 2007). However, Brandrud et al. (2020) found that omitting from their analysis a few accessions of D. maculata collected in eastern Europe was sufficient to alter inferred relationships such that D. maculata (plus D. foliosa) was perceived as sister to D. fuchsii plus D. saccifera s.l. (Fig. 3B). This topology was eventually selected as their preferred hypothesis by Brandrud et al. (2020, their fig. 3), presumably because the sister pairing of $D$. fuchsii plus D. saccifera received stronger statistical support in their chosen molecular tree. We can now see that their preferred topology was arguably more consistent with morphological similarity (Fig. 4), and a further advantage was a more homogeneous mutation rate across the clade than the accelerated mutation rate within D. maculata s.s. implied by Fig. 3A. On the other hand, preference would normally be given to an analysis that maximised taxon sampling (i.e. Fig. 3), irrespective of other factors; there is no compelling reason given by Brandrud et al. (2020) for 


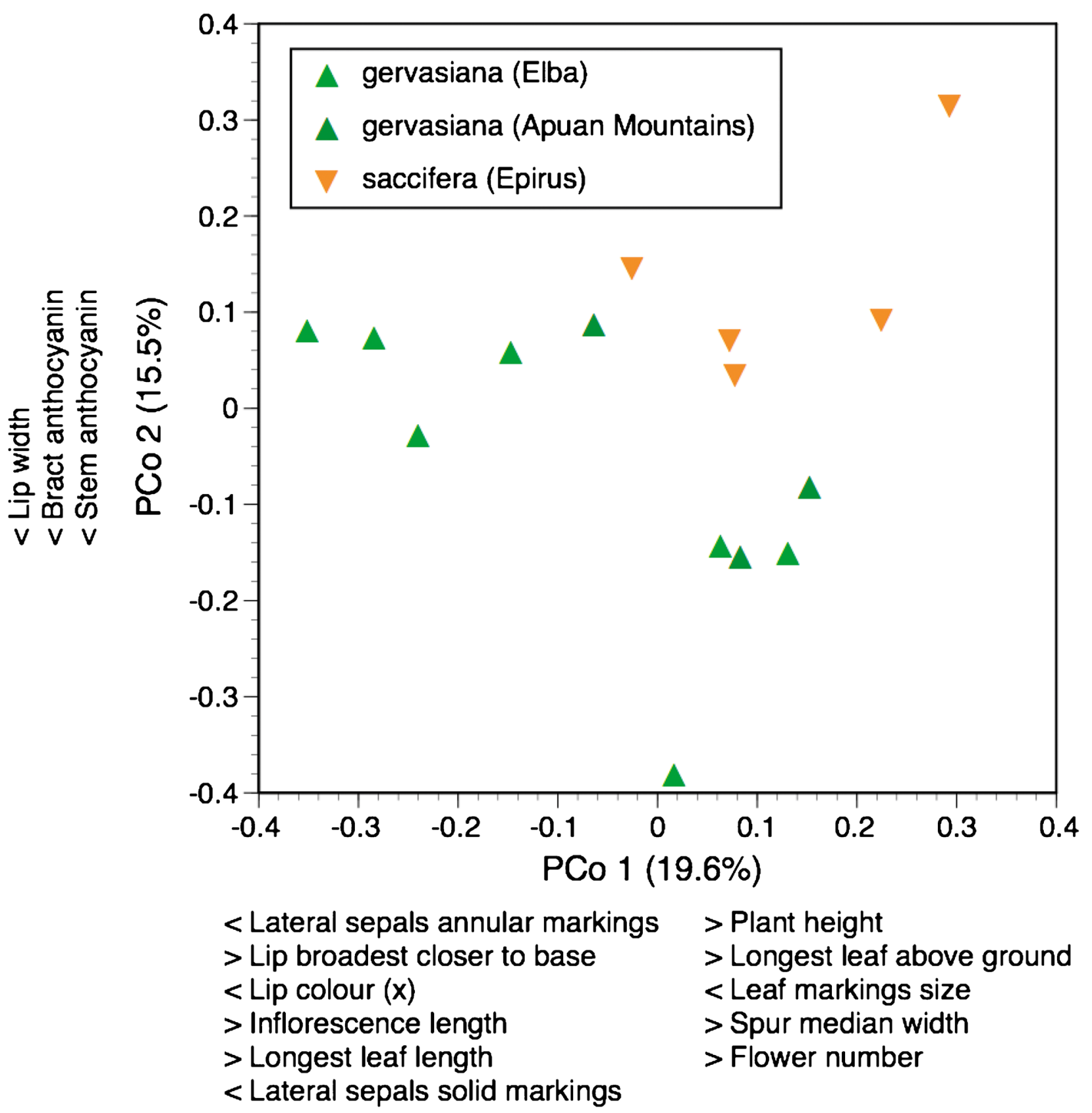

Fig. 12. Plot of principal coordinates 1 vs 2 for 45 morphometric characters and 15 individuals of Dactylorhiza saccifera and D. gervasiana only. Characters contributing to the coordinates are listed in order of decreasing importance.

removing eastern samples of D. maculata s.s. from their analysis. Their preferred topology also mirrored relationships recovered from a previous molecular study, but in this case support came only from the comparatively weakly sampled, ITS + ETS-based tree of Devos et al. (2006a, 2006b).

Previous DNA-based studies of this clade have either (a) analysed only one plant each of Dactylorhiza maculata s.s. and D. foliosa, precluding assessment of the possible monophyly of either species (Inda et al. 2012; Tang et al. 2015), (b) analysed a few samples of maculata s.s. but only one of foliosa, yielding results that were inevitably ambiguous in terms of species circumscription because the monophyly of $D$. folios $a$ was not tested (Bateman et al. 2003; Pillon et al. 2007), or (c) analysed small numbers of both species, resulting in stronger resolution of the two species as mutually monophyletic sister groups (Devos et al. 2006a, 2006b). However, that result is now contradicted by the much more character-rich matrix of Brandrud et al. (2020), in which two analysed accessions of D. foliosa (only one is shown in their Fig. S1, reproduced here as Fig. 3A) became nested deeply within D. maculata, thereby rendering $D$. maculata unequivocally paraphyletic in 


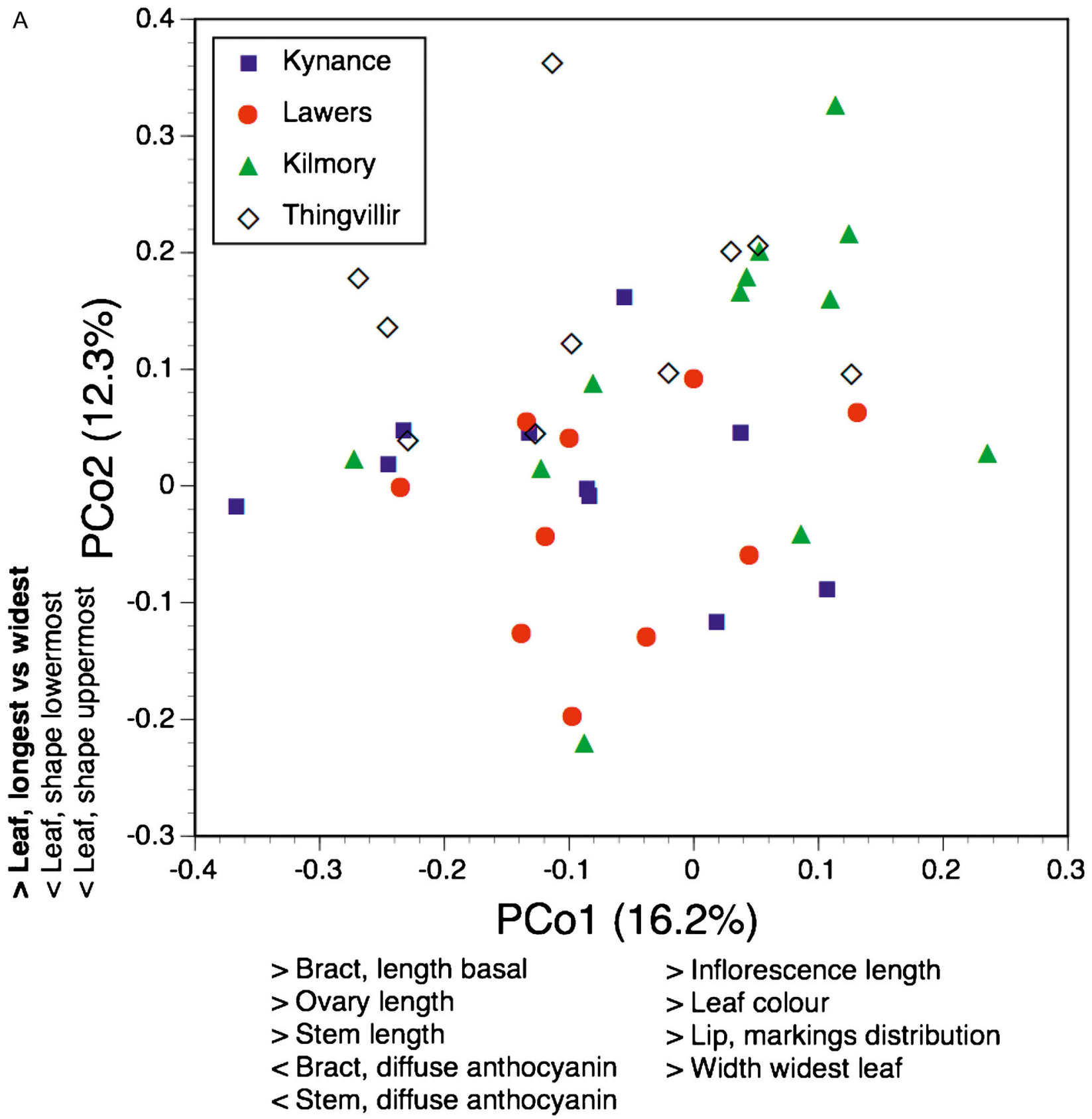

Fig. 13. Plot of principal coordinates A 1 vs 2; B (overpage) 3 vs 4 for 45 morphometric characters and 42 individuals of Dactylorhiza maculata "ericetorum" (Kynance, Lawers), "rhoumensis" (Kilmory) and "islandica" (Thingvillir). Characters contributing to the coordinates are listed in order of decreasing importance; dominant variables are shown in boldface.

the context of their particular data matrix. This DNAbased result is likely to disconcert morphologists familiar with the large, lightly marked or unmarked labella and luxuriant, typically unmarked leaves that characterise $D$. foliosa.

Similar ambiguity among previous molecular studies affects the phylogenetic placement of Dactylorhiza saccifera s.l. It has variously been placed (a) with poor statistical support as sister to all other members of the
D. maculata group (Bateman et al. 2003; Pillon et al. 2006, 2007; Tang et al. 2015), thus broadly mirroring the reduced-sample topology of Brandrud et al. (2020), (b) as sister to maculata plus foliosa with strong support (Inda et al. 2012), or (c) as sister to fuchsii with strong support (Devos et al. 2006a, 2006b), thus broadly mirroring the topology preferred by Brandrud et al. (2020) (i.e. Fig. 3B). However, the Brandrud et al. trees — both their all-sample and reduced-sample versions 

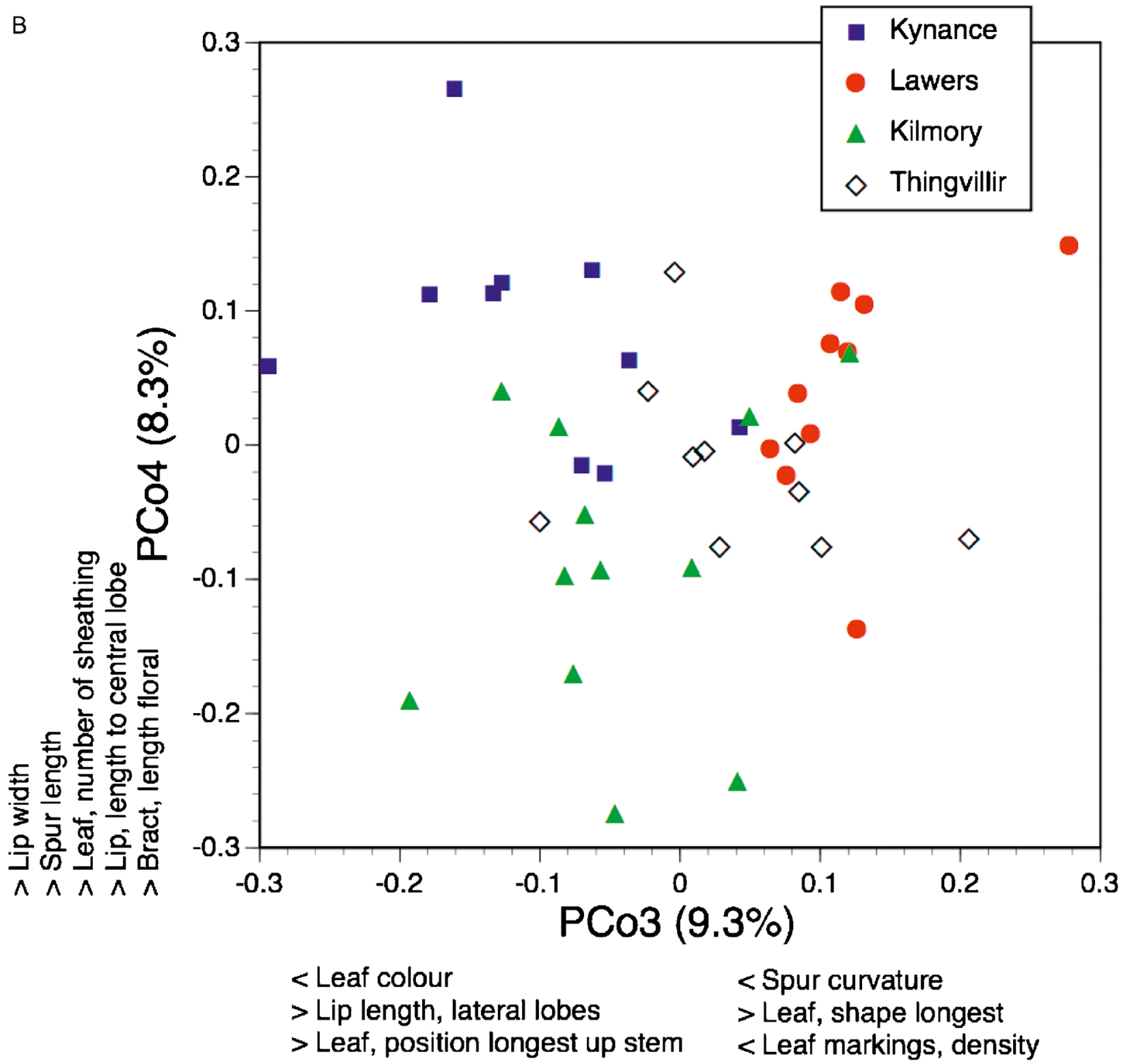

Fig. 13. (continued)

— contradict all previous studies in suggesting diphyly of D. saccifera s.l., not only separating western from eastern populations (i.e. gervasiana from saccifera s.s.) but also implying that these two taxa could have separate origins. Consequently, the trees show D. saccifera s.l. as paraphyletic relative to either a wellsupported monophyletic D. fuchsii (Fig. 3B) or a less well-supported D. fuchsii plus D. maculata-foliosa (Fig. 3A).

Within Dactylorhiza saccifera s.l., monophyly of the eastern European clade that constitutes D. saccifera s.s. (four samples, representing north-central Greece, Bulgaria, Georgia and north-central Turkey) receives strong statistical support, but not so that of the central Mediterranean clade within saccifera s.l. - the taxon discussed here under the name gervasiana (three samples: two from central Italy plus one from Corsica). And more crucially, the branch separating saccifera s.s. from gervasiana is also less well-supported statistically.

Some statistically supported structure is evident within the molecular data for Dactylorhiza maculata s.s., but it is difficult to interpret beyond noting the existence of a moderately well-supported Atlantic clade that encompasses all plants sampled in Madeira (i.e. foliosa), Portugal, the British Isles, Faroe Islands and Iceland (Fig. 3A). Surprisingly, even less structure is evident within D. fuchsii, most internal branches failing to achieve even $50 \%$ bootstrap support.

Overall, the molecular topologies obtained for the maculata group by Brandrud et al. (2020) are here 
judged credible but by no means proven, nor would I wish to adjudicate between the preferred and alternative topologies illustrated in the 2020 paper that differ radically in the placement of Dactylorhiza maculata s.s. plus D. foliosa (cf. Fig. 3A vs 3B); the two options appear approximately equally probable if judged on molecular evidence alone.

\section{Critique of the morphometric results}

The approach to morphometric data analysis adopted here is recursive: first take a multivariate overview of available data for Section Maculatae (Fig. 4), explore some of the more informative characters identified by that analysis (Figs $5-10$ ), and then conduct more focused ordinations of those taxonomic questions of greatest interest: comparing saccifera s.l. with fuchsii (Fig. 11), comparing saccifera s.s. with gervasiana (Fig. 12), and exploring variation among named taxa within maculata s.s. (Fig. 13).

\section{Are the sample sizes sufficient to justify even tentative conclusions?}

If sampling for the molecular phylogenetic study of Brandrud et al. (2020) is undesirably (though understandably) sparse, that underpinning the present morphometric analysis is open to the same accusation. I normally aim to measure in situ ten plants per population from at least eight populations of any target species if I am to view that species as having been well characterised. As I have available data for 22 populations of Dactylorhiza fuchsii and 24 populations of D. maculata s.s. from the British Isles (most of which featured in Bateman \& Denholm 1989), it would have been easy for me to include in the present taxon-wide analysis more than one British population of $D$. fuchsii or of D. maculata s.s. (Fig. 4), but to do so would simply have swamped the morphological signal provided by the few previously measured plants of D. saccifera s.l. My main defence for drawing even tentative conclusions from the analyses presented in Figs $4-11$ is that experience has taught me that although increasing sample density can often eliminate morphological discontinuities that were suggested by earlier, less well-sampled analyses, the converse is not true increasing sampling of plants will not generate discontinuities where they were not previously evident (although increasing the number of characters scored can, in theory, do so). Nor does increased sampling of populations tend to alter the relative distances separating centroids of variation among the sampled taxa (more detailed discussions of these crucial but rarely addressed issues are given in Bateman 2001, 2011, 2021).

\section{Dactylorhiza foliosa is a morphological outlier within Section Maculatae}

The recursive protocol chosen for the multivariate analysis was necessitated by the comparatively distinct morphology of Dactylorhiza foliosa (Fig. 1F). Although evidently a member of Section Maculatae (Fig. 3), this taxon is separated from all other taxa by a clear discontinuity on the first principal coordinate and from D. maculata s.s. (within which it is deeply embedded in the RAD-seq tree) on the second coordinate (Fig. 4). Its labella are of similar shape to those of D. maculata s.s. (Fig. 6) but considerably larger (Fig. 5, inset) and somewhat deeper in background colour (Fig. 8), and its labellar spurs are of similar diameter but somewhat shorter (Fig. 7). Typical plants are also, as the name suggests, more foliose (Fig. 9). Lateral sepals are less often connivent with the median sepal, leaves are reliably unmarked, and bracts reliably possess barrel-shaped marginal cells.

\section{Morphometric comparison suggests D. saccifera s.l. and} D. fuchsii are closely related sisters

Dactylorhiza saccifera s.l. partially overlaps D. fuchsii in the principal coordinates plot of all species (Fig. 4). This is not surprising, given similarities such as deeply incised, heavily marked labella, comparatively broad spurs (especially saccifera), leaves relatively planar and often heavily marked with transverse bars, and bract marginal cells distinctly angular. These features seemed likely to imply that these species are sisters, as indicated in the preferred RAD-seq tree of Brandrud et al. (2020) (Fig. 3B). Multivariate comparison of these taxa was therefore performed (Fig. 11), seeking distinguishing characters.

In Fig. 11, three groups of plants - English fuchsii, Austrian fuchsii and aggregated saccifera s.l. - do not overlap but nor are they separated by pronounced discontinuities. I know from additional experiments conducted during this study that including in the analysis further populations of Dactylorhiza fuchsii removes any possibility of morphological discontinuities being recognised within this species. Also, sufficient morphological descriptions and images of saccifera s.l. are available to suggest that increased sampling would similarly expand the morphospace that this species occupies on the resulting plot. Interpreted literally, Fig. 11 suggests that the two populations of $D$. fuchsii are as morphologically distinct from each other as they are from $D$. saccifera s.l.

Indeed, the smaller, paler flowers (Figs 5, 7, 8) and compact growth form that differentiate this English fuchsii population from the Austrian fuchsii population may reflect their contrasting habitats, the former occupying exposed chalk downland but the latter occurring in open woodland conditions. However, the greater average flower size (Figs 5, 7) and vegetative vigour (Figs 8 - 10) of Dactyorhiza saccifera s.l. persisted when populations of D. fuchsii from more closely similar habitats were used as comparators. To 
summarise, when subject to well-informed interpretation, the available morphometric data indicate the existence of two closely related species, D. fuchsii and D. saccifera s.l., that differ subtly but reliably in several morphological features.

\section{Cryptic taxa or non-taxa?}

In contrast, the morphometric data cannot discern any meaningful morphological difference between saccifera s.s. and gervasiana (Figs $4-12$ ), despite their resolution as two clades in the RAD-seq tree (Fig. 3). Similarly, the multivariate ordination examining named taxa within Dactylorhiza maculata s.s. (Fig. 13) failed to distinguish from ericetorum the supposed island endemics rhoumensis (from Hebridean Rum) or islandica (from Iceland). Indeed, islandica appears to be morphologically typical of populations of D. maculata s.s. from north-western Europe, an observation given greater relevance by the fact that the holotype of $D$. (formerly Orchis and Dactylorchis) maculata was collected in Sweden (reviewed by Vermeulen 1968). In these instances at least, morphological and molecular data-sets agree that levels of divergence are low.

Taking all these factors into account, the morphometric results obtained during the present study render credible (though not unequivocally proven) a species-level distinction between fuchsii and saccifera s.l. However, they offer little encouragement for the putative species-level separation of gervasiana from saccifera s.s. that was suggested by the molecular trees of Brandrud et al. (2020) (Figs 11, 12), nor do they encourage taxonomic subdivision within Dactylorhiza maculata s.s. (Fig. 13). But they do clearly demonstrate $D$. foliosa to be by far the most distinct taxon analysed (Fig. 4), in stark contrast with the decidedly modest divergence from closely related lineages of $D$. maculata s.s. identified through the molecular data (Fig. 3).

\section{Invoking additional categories of potentially relevant data}

\section{Ploidy}

At this point in the present discussion we should consider the significance of the ploidy transitions, mainly rom diploidy $(2 n=40)$ to tetraploidy $(2 n=$ 80), that have made Dactylorhiza such a popular study group for evolutionary biologists (e.g. HeslopHarrison 1954, 1968; Hedrén et al. 2008; Paun et al. 2010; Balao et al. 2016, 2017; Brandrud et al. 2020). Most attention has been paid to the multiple origins of allopolyploid taxa (variously viewed as species or subspecies) generated through repeated hybridisation between members of the maculata and incarnata groups. But it has also long been known that maculata s.s. is an autotetraploid (Hagerup 1944; HeslopHarrison 1948, 1951; Aagaard et al. 2005; Foelsche \&
Cord-Landwehr 2012) - one that is presumed to have evolved from an ancestor resembling D. fuchsii or perhaps $D$. saccifera.

All segregates within the maculata group (such as ericetorum and elodes) that have been studied for ploidy level have also been shown to be tetraploid (summarised by Averyanov 1990; Eccarius 2016). In contrast, Dactylorhiza fuchsii maintains both diploid and tetraploid cytotypes, which occasionally interact to produce triploids that have been unequivocally documented in both Scandinavia (Stahlberg \& Hedrén 2008) and the Alps (Vöth 1978). Nonetheless, diploids appear to dominate across much of the range of the species. A similar situation may pertain within D. saccifera s.l., where most of the limited available evidence supports diploidy in both Italy and Greece (Mazzola et al. 1981; D'Emerico et al. 2002; Cozzolino et al. 2004; Hedrén et al. 2007; Delforge 2016; Eccarius 2016) but there have also been occasional unsubstantiated reports of tetraploids (Soó 1980; Sundermann 1980; Averyanov 1990). Dactylorhiza foliosa has repeatedly been stated to be diploid (Sundermann 1980; Averyanov 1990; Delforge 2016; Eccarius 2016; Brandrud et al. 2020), an assessment that can be traced back to a single specimen examined by Vermeulen (1947, 1978). This issue is particularly relevant because RAD-seq trees (Fig. 3) embed foliosa deeply within the autotetraploid maculata s.s., yet basic evolutionary theory dictates that diploid lineages should not originate from within tetraploid species. Recent studies suggest that, as usual, the story may be more complex than previously thought.

\section{Intrinsic and extrinsic sterility barriers}

The frequent occurrence of natural hybrids (e.g. Stahlberg 2009; Stace et al. 2015) and readiness of the species to cross and backcross under controlled conditions all argue against the presence of effective intrinsic sterility barriers within Section Maculatae, and the approximately 20 second duration of caudicle curvature that follows removal of the pollinaria from the gynostemium (Claessens \& Kleynen 2011) is sufficient to permit frequent geitonogamy. Species of Section Maculatae are, to put it bluntly, highly promiscuous.

Pollinator specificity appears unlikely to play a significant role in circumscribing species within Section Maculatae. All are typical facultatively allogamous, food-deceptive orchid species and so attract as pollinators a wide range of Coleoptera, Diptera and Hymenoptera, leading to moderate frequencies of fruit-set. Claessens \& Kleynen (2011) listed 35 species of 23 genera as pollinators of Dactylorhiza fuchsii and 22 species of 14 genera as pollinators of D. maculata s.s., the two pollinator spectra greatly overlapping in composition (see also Vöth 1999). Although only one species each of Diptera and Hymenoptera have been 
recorded as pollinating D. foliosa (Fernandes et al. 2005) on the Atlantic island of Madeira, both of the genera implicated are also known to pollinate both D. fuchsii and D. maculata s.s. Sadly, no pollinator data appear to be available for D. saccifera s.l.

Synthesis: what is the optimal species-level taxonomy within the Dactylorhiza maculata group?

\section{Rules for applying monophyly}

I have long argued (e.g. Bateman 2009, 2012a) that converting a reconstructed phylogeny into a justifiable hierarchical classification requires, in order of priority, (1) the application of monophyly, (2) pruning off monophyletic groups on branches of the tree where branch length is comparatively long and therefore statistical support is usually comparatively strong, and (3) minimising situations where two or more different ranks are placed on the same branch of the tree (notably genus and species - a distinction not in question here, where all relationships are indisputably infrageneric), because such a situation renders one of those ranks superfluous.

If we attempt to apply the rules of monophyly and robustness of internal tree branches to the Dactylorhiza maculata group, as resolved in the molecular phylogeny here reproduced as Fig. 3, two species-level classifications are theoretically permitted: (A) Recognise four species: maculata (including foliosa), saccifera s.s., gervasiana, fuchsii (i.e. dividing up the tree on branches A - D in Fig. 3A); (B) Recognise only a single species: D. maculata sensu latissimo (i.e. cutting branch $\mathrm{E}$ in Fig. 3A).

At this point, it is worth noting that although both of the legitimate options leave open a vast spectrum of possible (albeit only trivially distinct) infraspecific classifications, no classification into five, three or two species is strictly permitted by combining Rules 1 and 2. Conversely, it is also worth noting that no previously published classification has proposed either option A or option B.

\section{Historical context}

Among the myriad of previous classifications published for the Dactylorhiza maculata group, none has treated D. foliosa as a subspecies of D. maculata. Indeed, as far as I can determine, only once has foliosa been viewed as being infraspecific: it was treated as a subspecies of the marsh-orchid D. incarnata by that greatest aficionado of the subspecies rank, Sundermann (1975). Five years later, even he changed his mind and raised foliosa to a full species - one of only six European species that he was willing to recognise within the genus Dactylorhiza (Sundermann 1980).
If we temporarily set aside the phylogenetically troublesome but taxonomically stable Dactylorhiza foliosa, reliably treated as a full species by previous authors, post-war classifications of the remaining members of the D. maculata group can be summarised in four categories:

(1) maculata, saccifera and fuchsii recognised as species but alongside additional infrageneric taxa within the Dactylorhiza maculata s.l. group (Vermeulen 1947; Senghas 1968; Landwehr 1977; Soó 1980; Kreutz 2004; Baumann et al. 2006; Eccarius 2016) - a treatment also implied by the discussion in Stahlberg \& Hedrén (2008, 2010). Excluding nominate taxa, Landwehr (1977) not only described but also painted an additional 12 subspecies, 14 varieties and eight formae that he assigned to the maculata group.

(2) maculata, saccifera and fuchsii recognised as species but alongside additional species within the Dactylorhiza maculata s.l. group (Averyanov 1990; Bournérias \& Prat 2005; Delforge 2016). An additional 12 taxa of D. maculata sensu latissimo were treated as full species by Delforge (2016) and an additional 14 by Averyanov (1990) (these were taxa of comparatively restricted geographical distributions: triphylla, urvilleana, nieschalkiorum, okellyi, hebridensis, psychrophila, maculata, maurusia, elodes, schurii, transsilvanica, ericetorum, sudetica, kolaensis, islandica).

(3) maculata and saccifera recognised as species but fuchsii relegated to a subspecies (or lower rank) within D. maculata (Baumann \& Künkele 1982; Buttler 1991).

(4) maculata, saccifera and fuchsii recognised as subspecies of D. maculata sensu latissimo but most commonly placed alongside multiple additional subspecies within the D. maculata group (Nelson 1976; Sundermann 1980; Grünanger 2016; Kühn et al. 2019).

Which, if any, of these four options best fits the available data? A few authors have opted for an egalitarian classification of all named taxa being subspecies, varieties, forms or mere synonyms within a single morphologically, cytologically and molecularly variably pan-Eurasian species Dactylorhiza maculata sensu latissimo (e.g. Buttler 1991; Stahlberg \& Hedrén 2008). The argument for recognising only a single species (option 4) does have some appeal, given the perplexing morphological, molecular and chromosomal complexity now demonstrated to characterise the group. But in practice, such a decision is actually a counsel of despair — it is a nihilistic "solution" that simply transfers the many problems already elucidated to shallower taxonomic levels, genuinely solving none of them. Classifications that divide the D. maculata group into one species and six subspecies (Sundermann 1980) cannot make adequate use of the ability of Linnean classification to represent biological entities in a hierarchical framework. Nor, 
admittedly, can classifications that divide Section Maculatae into 15 species (Delforge 2016).

\section{Dactylorhiza foliosa undoubtedly belongs within Section Maculatae}

Surveying many formal infrageneric classifications published for the Dactylorhiza maculata group shows that $D$. foliosa was not placed within the group by any author other than Averyanov (1990) and arguably Eccarius (2016), who placed D. foliosa alongside $D$. fuchsii and D. saccifera but not D. maculata s.s. In the late 19th and early-mid 20th Centuries (a time when, unlike today, infrageneric but supraspecific classification of species groups into subgenera, sections and subsections was still widely practised) most classifications placed foliosa within a taxonomic subsection or series of the genus Dactylorhiza outside Section Maculatae, most commonly categorised with the allopolyploid marsh-orchid D. elata (e.g. Vermeulen 1947, 1977; Soó 1960; Senghas 1968; Nelson 1976) or, on one occasion, with the diploid marsh-orchid D. incarnata (Sundermann 1975).

Ample molecular data have since accumulated to demonstrate the close relationship between Dactylorhiza foliosa and D. maculata s.l., including AFLPs (Hedrén et al. 2001), targeted gene sequences within nuclear (e.g. Bateman et al. 2003) and plastid (e.g. Stahlberg \& Hedrén 2008) genomes, and nextgeneration nuclear sequencing through RAD-seq (Brandrud et al. 2020).

Even from a morphological perspective, classifying Dactylorhiza foliosa with marsh-orchids such as D. elata or D. incarnata, rather than spotted-orchids of the D. maculata group, ignores some of the best (if not yet widely recognised) morphological clues of its true affinity, such as possessing several bract-like leaves and narrow labellar spurs resembling those of $D$. maculata s.s. Indeed, D. foliosa grouped with $D$. fuchsii (the only other member of Section Maculatae analysed) in the morphological cladistic analyses of Bateman et al. (2018b). The frequent infrageneric misclassification of D. foliosa constitutes a classic example of taxonomists deciding to prioritise for classificatory purposes suboptimal morphological characters.

\section{Dactylorhiza fuchsii is unequivocally a bona fide species (but not a bona fide section)}

Ironically, the taxon with the strongest claim to species-level status on the evidence presented by Brandrud et al. (2020) is often refused that status by Continental orchid specialists, specifically Dactylorhiza fuchsii. It is statistically well-supported as being both well-separated from the other taxa and monophyletic, but in contrast, relationships suggested by taxonomists within D. fuchsii appear weak and show little if any interpretable structure (Fig. 3). In other words, RADseq data show $D$. fuchsii as being both distinct and cohesive, a conclusion reinforced by all previous DNAbased studies. Moreover, similar conclusions have been drawn from previous morphometric studies featuring larger (if less geographically widespread) samples (Bateman \& Denholm 1989; Tyteca \& Gathoye 1989; Dufrene et al. 1991; Tyteca \& Dufrene 1993). Some workers argue that, although D. fuchsii is universally accepted as a bona fide species by British and Irish authors, it is not morphologically distinguishable from D. maculata s.s. in regions of Europe viewed as more problematic, notably Scandinavia (Heslop-Harrison 1951; Stahlberg \& Hedrén 2008, 2010) and the Alps (Vöth 1978; Gölz \& Reinhard 1997; Stahlberg \& Hedrén 2010). However, my own field experience suggests that, even in the Alps, characters shown to be effective within the British Isles, such as labellum shape, spur width, and leaf width and shape (Bateman \& Denholm 1989, 2003), function acceptably well to distinguish these two species. I consider that molecular and morphometric data together fully justify recognition of D. fuchsii as a bona fide (and monophyletic) species.

In contrast, it is difficult to find a scientific justification supporting Eccarius' (2016) decision to create a new taxonomic section, Fuchsiae, rooted in Dactylorhiza fuchsii but also containing D. saccifera s.l. and $D$. foliosa. The new section was segregated from section Maculatae to leave only D. maculata s.s. plus, bizarrely, D. urvilleana - actually an allopolyploid lineage originating in Asia Minor as a result of hybridisation between $D$. saccifera s.s. and D. euxina of the incarnata group (Brandrud et al. 2020). The main argument put forward for separating D. fuchsii from D. maculata s.s. at this level was the repeated contribution of the former to the famous Eurasian allopolyploid complex formed with members of the D. incarnata-euxina clade, but in fact $D$. maculata s.s. has similarly acted as ovule-parent for allopolyploids such as D. sphagnicola, D. kerryensis and D. elata (Pillon et al. 2007; Brandrud et al. 2020).

Dactylorhiza foliosa is probably a species (with apologies to monophyly)

Also well-supported as monophyletic is the maculatafoliosa clade. However, this group differs from Dactylorhiza fuchsii in consisting of two taxa that have been almost universally regarded as two distinct species by previous authors; here, the monophyletic $D$. folios $a$ is deeply nested within, and thus renders paraphyletic, D. maculata s.s. (Fig. 3). Monophyly therefore requires that foliosa be treated as an infraspecific taxon within D. maculata (or alternatively that D. maculata s.s. should be divided into several more localised monophyletic species, such as islandica and ericetorum). Can, and should, anything be done to prevent foliosa from suffering the ignominy of taxonomic demotion to subspecies? Or, to phrase the 
question another way, are there mitigating circumstances that might rescue foliosa as a bona fide species?

The RAD-seq tree (Fig. 3A) suggests that Dactylorhiza foliosa is the pinnacle of evolution within the Maculata clade. Significantly, its closest neighbours in the molecular phylogeny are taxonomic segregates of D. maculata s.s. that are endemic to the Atlantic coasts of Europe: maurusia in northwest Africa, caramulensis in Iberia, ericetorum in the British Isles and islandica in Iceland. These are taxa typically treated as either species (Averyanov 1990; Delforge 2016) or subspecies (Senghas 1968; Kreutz 2004; Baumann et al. 2006; Eccarius 2016; Kühn et al. 2019), although their collective value as taxa of any rank was questioned on both morphological and molecular grounds when reviewed by Bateman \& Denholm (2003). Crude comparisons based on published descriptions suggest that caramulensis and maurusia are probably the named taxa that are most morphologically similar to foliosa. Moreover, morphometric data gathered in a previous study of the group suggested that caramulensis is at least as morphologically distinct as D. fuchsii, D. gervasiana and D. maculata s.s. (Tyteca \& Gathoye 1989; Dufrene et al. 1991; Tyteca \& Dufrene 1993). But although the two accessions of caramulensis analysed by Brandrud et al. (2020) formed a monophyletic pairing with strong statistical support, they differed very little in RAD-seq data from single accessions of other taxa of maculata s.l. that characterise the Atlantic seaboard, namely islandica and ericetorum; their respective levels of molecular differentiation are consistent with conspecificity. Thus, these taxa represent yet another example of contrast between morphological and molecular levels of disparity.

Brandrud et al. (2020) argued that the close relationship between Dactylorhiza foliosa and D. maculata s.s. is most parsimoniously explained by the two taxa sharing a diploid ancestor with similar genetic properties but since rendered extinct (or at least molecularly unrecognisable) in mainland $\mathrm{Eu}-$ rope. Brandrud et al. (2020) estimated divergence of the foliosa-maculata s.s. clade at approximately $4 \mathrm{Ma}$, and suggested that $D$. folios $a$ (perhaps more accurately described as the lineage leading to $D$. foliosa) could have migrated to Madeira soon after the island emerged from the Atlantic at about $5 \mathrm{Ma}$, taking advantage of a chain of "stepping-stone" islands available to the orchid at that time. However, a similar thesis involving a similar timescale has also been applied previously to the orchid Himantoglossum metlesicsianum, endemic to the nearby Canary Islands but sister to, and presumably derived from, the widespread mainland species $H$. robertianum. Yet these two Himantoglossum species show considerable divergence in nrITS sequences that is not mirrored in the negligible nrITS disparity evident between $D$. foliosa and D. maculata s.s. (Bateman et al. 2003). It is therefore possible that the ancestor(s) of D. foliosa reached the volcanic Macaronesian island of Madeira much more recently than $4 \mathrm{Ma}$, via seed carried by wind or birds from the western seaboard of Iberia or northwest Africa.

In either scenario, the immigrant lineage would likely experience a genetic bottleneck combined with relaxed selection permitted by new ecological opportunities (i.e. the founder effect), which could permit rapid divergence in morphological characters that are readily evolutionarily modified, thus satisfactorily explaining the striking incongruence between its substantial morphological disparity and limited molecular disparity. In other words, Dactylorhiza foliosa may be a classic case of an immigrant rapidly evolving into a comparatively morphologically distinct island endemic. On the other hand, a recent population genetic study revealed foliosa to be genetically diverse and ecologically well-established (Hedrén 2021). Whichever hypothesis of its origin is accepted, species status for $D$. foliosa has the unfortunate consequence of rendering $D$. maculata s.s. paraphyletic.

\section{Dactylorhiza maculata s.s. is a single (paraphyletic) species containing subordinate taxa}

The combination of Dactylorhiza maculata s.s. plus D. foliosa is well-supported as a clade and readily distinguishable from all other species of Section Maculatae on molecular grounds (Fig. 3). Current evidence suggests that D. maculata s.s. is uniformly tetraploid, with a $1 \mathrm{C}$ value slightly smaller than twice that of the usually diploid D. fuchsii (Aagaard et al. 2005). And sufficient morphometric data exist to demonstrate that $D$. maculata s.s. can be distinguished reliably from $D$. fuchsii at the population level (Fig. 4), provided that this is done using a combination of the most effective distinguishing characters (Figs 6 - 9) (Bateman \& Denholm 1989; Tyteca \& Gathoye 1989; Dufrene et al. 1991; Stahlberg \& Hedrén 2008). Admittedly, hybrids between these two species cannot be identified with confidence in the absence of genetic or karyotypic data, but the contrasting habitat preferences of the two species undoubtedly help to limit gene flow between them.

Evolutionary interest in this species focuses on identifying the most likely diploid ancestor of Dactylorhiza maculata s.s. Early studies assumed from morphological comparison that the ancestor was, or at least resembled, D. fuchsii (Hagerup 1944; HeslopHarrison 1951, 1957). More recently, genetic data derived first from targeted Sanger sequencing (Stahlberg \& Hedren 2008, 2010) and then RAD-seq (Brandrud et al. 2020) have all shown close, wellsupported links between western populations of D. maculata s.s. and the diploid D. foliosa. 
Adjudicating on the remaining taxa molecularly embedded within Dactylorhiza maculata s.s. and analysed here morphometrically is more straightforward; taxa such as islandica and rhoumensis show no greater disparity, either molecularly or morphologically, than is typically detected between different populations of the same orchid species. This statement applies to both molecular data and - in cases where morphometric data are available - to morphology, thus comprehensively rejecting their claim for taxonomic recognition. One possible complication that should be mentioned is that most authors regard all Icelandic dactylorchids as being attributable to islandica (e.g. Delforge 2016), including the Icelandic national flora (Kristinsson 2010), whereas Eccarius (2016, p. 346) considered islandica to consist of a few rare populations occurring within a background of typical D. maculata s.s. on Iceland. A broader morphometric survey encompassing a larger number of these infraspecific taxa remains desirable. Ideally, any future study would compare caramulensis and maurusia with D. foliosa, aiming to determine whether or not they help to bridge the otherwise large morphological gap to D. maculata sensu strictissimo. The present data reinforce the opinion of Bateman \& Denholm (1989, 2003) that British populations of D. maculata s.s. collectively lack taxonomically meaningful structure, and question whether all 10 subspecies recognised by Eccarius (2016) have genuine value.

\section{Dactylorhiza gervasiana may (or may not) be a cryptic species distinct from $D$. saccifera s.s.}

Having overridden monophyly in the case of Dactylorhiza foliosa vs D. maculata s.s., can monophyly regain the upper hand during our final challenge: deciding whether gervasiana merits species-level separation from $D$. saccifera s.l.? This decision requires the wisdom of Solomon because the genotypic and phenotypic data provide such strongly contradictory signals. In the absence of the RAD-seq data, it would be a brave morphologist who was willing to distinguish at species level two taxa primarily through the differences in leaf width documented here, particularly as both taxa appear to share the character of leaves that increase remarkably little in width as they increase in length (regression lines in Fig. 9). The morphometric differences documented here are indisputably at a level expected among conspecific populations.

Considering further the genetic disparity separating gervasiana from saccifera s.s., it may be relevant that studies of other European orchid genera have repeatedly identified the "Carpathian Divide" (Devey et al. 2009; Bateman et al. 2021; G. Sramkó, R. Bateman \& O. Paun unpublished). This zone extends northward from the Adriatic Sea across which European orchid species tend to show their greatest genetic disparity, perhaps reflecting northward migrations from con- trasting glacial refugia. Unsurprisingly, it is this zone that separates the eastern saccifera s.s. from the western gervasiana. Overall, it seems reasonable to conclude that gervasiana and saccifera s.s. (including bithynica and amblyoloba) are more likely than not to be monophyletic, and that saccifera s.l. is more likely than not to be paraphyletic. Nonetheless, given the small number of relevant samples analysed for DNA (seven) and the weak statistical support attracted by the two putative clades, these inferred relationships are not strongly supported and certainly cannot be viewed as definitive.

The genetic data are not encouraging with regard to claims of species status for either the north-western Turkish bithynica (Baumann 1983) or the Caucasian amblyoloba (Nevski 1935), as both plants are nested within the Bulgarian and Greek samples attributable to saccifera s.s. Morphometric data are needed from the Asia Minor segregates to enable comparison between genotype and phenotype, and to test the subspecific status awarded to these taxa by Eccarius (2016). Further taxa are relevant to this discussion, such as D. "cyrnea" — a putative autotetraploid endemic that co-occurs alongside Dactylorhiza gervasiana on Corsica (Foelsche \& Cord-Landwehr 2012). This taxon appears to me to be more appropriately assigned to $D$. maculata, but in the absence of both molecular analysis and multivariate morphometrics, my current opinion represents nothing more than mere guesswork.

\section{Broader Implications}

The net result of my determined attempt to logically integrate multiple datasets, primarily trees derived from RAD-seq nuclear DNA data and ordinations derived from in situ morphometric data, is the recognition of five species within Dactylorhiza section Maculatae (as outlined in Fig. 3). One of these species is undoubtedly paraphyletic relative to a rare island endemic, and a further two species appear cryptic and could yet be (re)amalgamated into a single species if the weak molecular evidence for paraphyly of the aggregate taxon fails future tests.

Note that the two competing species-level RAD-seq topologies published by Brandrud et al. (2020), offering radically different placements for the Dactylorhiza maculata s.s.-D. foliosa clade (Fig. 3A vs 3B), have no direct impact on species circumscription; they merely alter our perception of the relationships among the species once the circumscription of those species has been decided. Relationships among species are of course crucial if the primary aim to understand character evolution within the clade of interest - for example, to determine whether D. fuchsii evolved from within D. saccifera s.l., as is implied by Fig. 3B but not by Fig. 3A. It is easier to 
circumscribe species within a tree than it is to infer an evolutionary narrative regarding those species that can be defended with confidence.

In addition, this paper illustrates the fact that it is far easier to simply divide a molecular phylogeny into a hierarchy of taxa based on Bateman-style rules (sorry, I mean guidelines!) than it is to integrate data sets, when it becomes necessary to decide priorities among contrasting categories of data that differ so strongly in the nature of their constraints. The greater the difference in relative degrees of disparity separating putatively circumscribed taxa in different data categories, the more difficult it becomes to prioritise one category over the others. This statement is especially true if the molecular tree in question is of the old-fashioned typological variety (e.g. Bateman et al. 2003), each putative taxon being represented by a single plant in an approach that simply assumes species status rather than actually testing it. Certainly, any serious attempt at circumscription through multiple data categories greatly complicates the rules needed to both determine and justify the resulting classification from population-level sampling of the kind performed by Brandrud et al. (2020).

In the absence of combined morphological and molecular circumscription, species remain untested hypotheses. By definition, also remaining untested are any hypotheses of biological properties in general and speciation mechanisms in particular; until you have strong evidence that the taxa you are studying are bona fide species you can hardly discuss speciation processes from a position of knowledge. Such advances also necessitate adopting a monographic approach to classification that seeks to circumscribe multiple species on a level playing field - a crucial goal that cannot realistically be achieved by piecemeal description of "A new species of genus $\mathrm{X}$ from geographical region $\mathrm{Y}^{\prime \prime}$. It is evolutionary processes still active at the species level and below the "phylogenetic shallows" — that demand careful circumscription of taxa prior to attempting their classification (fortunately, cladistic principles can be applied less ambiguously at supraspecific levels). In the case of Section Maculatae, there is at least circumstantial evidence that island effects contributed to the origin of Dactylorhiza foliosa and autotetraploidy to the origin of D. maculata.

Within Section Maculatae, high morphological disparity has triumphed over low molecular disparity when justifying the continued recognition of Dactylorhiza foliosa as a full species, whereas I have reluctantly allowed levels of molecular monophyly that are worryingly weak to take precedence over a lack of morphological disparity when (provisionally) accepting $D$. gervasiana as a species separate from D. saccifera s.s. Unfortunately, these erstwhile species are perilously close to being cryptic sensu Bateman
(2021). The utility of $D$. gervasiana as a species worthy of mapping is therefore questionable; in the continued absence of a highly sophisticated field-based DNA sequencer (sensu Bateman 2016), the identification of a population as gervasiana rather than saccifera s.s. is likely to rest largely on the circular reasoning provided by the population in question being required to be located to the west of the "Carpathian Divide". Such a situation is no more intellectually appealing than identifying a bee orchid microspecies through its supposedly unique pollinator; extrinsic properties should not be prioritised above intrinsic characters when making taxonomic decisions.

A further problem is that it is difficult to envisage how we could develop a stronger test of the diphyly of Dactylorhiza saccifera s.l. All of the relevant taxa that appeared likely to achieve recognition as species were included in the Brandrud et al. (2020) analysis. Increasing the density of sampling - either the of number of populations per taxon and/or of the number of individuals per population - is unlikely to significantly alter the pattern of relationships already discerned or to strengthen their statistical support values. Also, it will be challenging to develop molecular techniques readily deployed at the population level that will yield larger numbers of discriminatory characters than can be achieved through RAD-seq, and the demonstrably high frequency of plastid capture during hybridisation events renders organellar genomes unreliable markers of lineage history in the taxonomic shallows, even when they are sequenced in their entirety through genome skimming (e.g. Bateman 2021).

I should return briefly to the "embarrassment" of allowing the species status widely attributed to Dactylorhiza foliosa of rendering paraphyletic another bona fide species, D. maculata s.s. At species level and below, any well-sampled monographic treatment incurs a high risk of being obliged to recognise at least one paraphyletic taxon. In the case of another taxonomically troublesome Eurasian orchid taxon, Epipactis section Epipactis, no less than six bona fide species were nested within their inevitably paraphyletic, putatively parental species - the geographically widespread E. helleborine (Sramkó et al. 2019; Bateman 2020). A similar fate has here befallen D. maculata s.s., but in this case - at least, on present evidence - only one bona fide species is nested within the residual paraphylon, namely $D$. foliosa. A second potential embarrassment is being obliged to recognise seemingly inseparable diploid and tetraploid plants of $D$. fuchsii as members of the same species, despite the likely reduction of gene-flow between the two cytotypes. Nonetheless, it has become abundantly clear that both Dactylorhiza s.l. and its sister genus, Gymnadenia s.l., include species that have been convincingly circumscribed, both 
morphologically and molecularly, but nonetheless encompass two or more ploidy levels (e.g. Stahlberg \& Hedrén 2008, 2010; Trávnicek et al. 2012).

Once population-level morphometric and genetic data have been systematically acquired for the clade under scrutiny, the applications for species status that are easiest to adjudicate with confidence are those where neither molecular nor morphological disparity exceed levels typical of those observed among conspecific populations. Such cases can be unequivocally rejected, an outcome that applies here to the so-called Dactylorhiza islandica. The proportion of such non-existent "Emperor's New Clothes" species that continue to be recognised in traditional formal classifications is likely to be greater than most taxonomists would wish to admit; I have little doubt that more plant species remain to be 'undiscovered' than remain to be 'discovered'. Unfortunately, any kudos available in modern, politically influenced taxonomy resides in describing new putative species (e.g. Antonelli et al. 2020; Cheek et al. 2020) rather than demonstrating that claims for species status made by previously described taxa cannot be upheld once confronted with solid biosystematic data - an equally important outcome from a scientific perspective, but one less appealing in the context of a cultural environment that rewards only unremitting positivism.

\section{Acknowledgements}

I thank Jess Stone and Kath Barrett for collecting the single sample of Dactylorhiza 'bithynica' analysed by Brandrud et al. (2020). Paula Rudall kindly provided the images in Fig. $1 \mathrm{~A}$ and $\mathrm{B}$ and critically read the manuscript, which later received the attention of two generous but anonymous reviewers. I am most grateful to my co-authors of the Brandrud et al. paper, notably Ovidiu Paun and Marie Brandrud, for allowing me to publish here a redrafted version of their Supplementary Figure S1. I also thank the Botanical Research Fund for a small fieldwork grant that facilitated collection of the data from the study population of islandica on Iceland in 2014.

Open Access This article is licensed under a Creative Commons Attribution 4.0 International License, which permits use, sharing, adaptation, distribution and reproduction in any medium or format, as long as you give appropriate credit to the original author(s) and the source, provide a link to the Creative Commons licence, and indicate if changes were made. The images or other third party material in this article are included in the article's Creative Commons licence, unless indicated otherwise in a credit line to the material. If material is not included in the article's Creative Commons licence and your intended use is not permitted by statutory regulation or exceeds the permitted use, you will need to obtain permission directly from the copyright holder. To view a copy of this licence, visit http://creativecommons.org/ licenses/by/4.0/.

\section{References}

Aagaard, S. M. D., Sastad, S. M., Greilhuber, J. \& Moen, A. (2005). A secondary hybrid zone between diploid Dactylorhiza incarnata ssp. cruenta and allotetraploid D. lapponica (Orchidaceae). Heredity 94: 488 $-496$.

Antonelli, A., Fry, C., Smith, R. J., Simmonds, M. S. J., Kersey, P. J., Pritchard, H. W. \& numerous coauthors (2020). State of the world's plants 2020. Chapter 1: Seeking out species before they disappear, pp. 4 - 9. Royal Botanic Gardens, Kew.

Averyanov, L. V. (1990). A review of the genus Dactylorhiza. In: J. Arditti (ed.), Orchid biology: reviews and perspectives, V, pp. 159 - 206. Timber Press, Portland.

Baird, N. A., Atwood, T. S., Currey, M. C., Shiver, A. L., Lewis, Z. A., Selker, E. U., Cresko, W. A. \& Johnson, E. A. (2008). Rapid SNP discovery and genetic mapping using sequenced RAD markers. PLoS One https://doi.org/10.1371/journal.pone.0003376

Balao, F., Tannhäuser, M., Lorenzo, M. T., Hedrén, M. \& Paun, O. (2016). Genetic differentiation and admixture between sibling allopolyploids in the Dactylorhiza majalis complex. Heredity 116: 351 - 361. , Trucchi, E., Wolfe, T. M., Hao, B.-H., Lorenzo, M. T., Baar, J., Sedman, L., Kosiol, C., Amman, F., Chase, M. W., Hedrén, M. \& Paun, O. (2017). Adaptive sequence evolution is driven by biotic stress in a pair of orchid species (Dactylorhiza) with distinct ecological optima. Molec. Ecol. 26: 3649 - 3662.

Bateman, R. M. (2001). Evolution and classification of European orchids: insights from molecular and morphological characters. J. Eur. Orch. 33: 33 - 119.

(2009). Evolutionary classification of European orchids: the crucial importance of maximising explicit evidence and minimising authoritarian speculation. J. Eur. Orch. 41: 243 - 318.

(2011). The perils of addressing long-term challenges in a short-term world: making descriptive taxonomy predictive. In: T. R. Hodkinson, M. B. Jones, S. Waldren \& J. A. N. Parnell (eds), Climate change, ecology and systematics, pp. 67 - 95. Systematics Association Special Volume 78. Cambridge University Press, Cambridge.

(2012a). Circumscribing genera in the European orchid flora: a subjective critique of recent contributions. Ber. Arbeitskreis. Heimische Orchid. 29: 92 - 124.

(2012b). Circumscribing species in the European orchid flora: multiple datasets interpreted in the context of speciation mechanisms. Ber. Arbeitskreis. Heimische Orchid. 29: 160 - 212. 
(2016). Après le déluge: ubiquitous field barcoding should drive 21st century taxonomy (Ch. 6). In: P. D. Olson, J. Hughes \& J. A. Cotton (eds), Next generation systematics, pp. 123 - 153. Cambridge University Press, Cambridge.

(2020). Implications of next-generation sequencing for the systematics and evolution of the terrestrial orchid genus Epipactis, with particular reference to the British Isles. Kew Bull. 75: 4 [22 pp.]

(2021). Species circumscription within 'cryptic' clades: a nihilist's view. In: A. Monro \& S. Mayo (eds), Cryptic species. Systematics Association Special Volume 89. Cambridge University Press, Cambridge. [in press: c. 40 pp.]

\& Denholm, I. (1985). A reappraisal of the British and Irish dactylorchids, 2. The diploid marsh-orchids. Watsonia 15: 321 - 355.

\& _ (1989). A reappraisal of the British and Irish dactylorchids, 3. The spotted-orchids. Watsonia 17: 319 - 349.

\& ____(2003). The Heath Spotted-orchid (Dactylorhiza maculata (L.) Soó) in the British Isles: a cautionary case-study in delimitating infraspecific taxa and inferring their evolutionary relationships. J. Eur. Orch. 35: 3 - 36.

Hollingsworth, P. M., Preston, J., Luo, Y.-B., Pridgeon, A. M. \& Chase M. W. (2003). Molecular phylogenetics and evolution of Orchidinae and selected Habenariinae (Orchidaceae). Bot. J. Linn. Soc. 142: 1 - 40.

Murphy, A. R. M., Hollingsworth, P. M., Hart, M. L., Denholm, I. \& Rudall, P. J. (2018b). Molecular and morphological phylogenetics of the digitatetubered clade within subtribe Orchidinae s.s. (Orchidaceae: Orchidinae). Kew Bull. 73: 54 [30 pp.]

\& Rudall, P. J. (2018). Clarified relationship between Dactylorhiza viridis and Dactylorhiza iberica renders obsolete the former genus Coeloglossum. Kew Bull. 73: 4 [21 pp.]

, Murphy, A. R. M., Cowan, R. S., Devey, D. S. \& Pérez-Escobar, O. A. (2021). Even whole plastomes are not enough: phylogenomic and morphometric exploration at multiple demographic levels of the bee orchid clade Ophrys sect. Sphegodes. J. Exp. Bot. 72: 654 - 681.

, Sramkó, G. \& Paun, O. (2018a). Integrating restriction site-associated DNA sequencing (RADseq) with morphological cladistic analysis clarifies evolutionary relationships among major species groups of bee orchids. Ann. Bot. 121: 85 - 105.

Baumann, H. (1983). Die Balkanisch-orientalischen Dactylorhiza-arten - ein vergleich. Mitteilungsbl. Arbeitskreises Heimische Orchid. Baden-Württemberg 15: $43-108$.

\& Künkele, S. (1981). Beiträge zur Taxonomie europäischer Orchideenarten. Mitteilungsbl.
Arbeitskreises Heimische Orchid. Baden-Württemberg 13: $337-374$.

\& ___ (1982). Die wildwachsenden Orchideen Europas. Kosmos, Stuttgart. , \& Lorenz, R. (2006). Orchideen Europas. Ulmer, Stuttgart.

Bournérias, M. \& Prat, D. (eds) (2005). Les orchidées de France, Belgique et Luxembourg (2nd edn). Biotope, Mezé.

Brandrud, M. K., Baar, J., Lorenzo, M. T., Athanasiadis, A., Bateman, R. M., Chase, M. W., Hedrén, M. \& Paun, O. (2020). Phylogenomic relationships of diploids and the origins of allotetraploids in Dactylorhiza (Orchidaceae): RADseq data track reticulate evolution. Syst. Biol. 61: 91 - 109.

Paun, O., Lorenz, R., Baar, J. \& Hedrén, M. (2019). Restriction-site associated DNA sequencing supports a sister group relationship of Nigritella and Gymnadenia. Molec. Phylogenet. Evol. 136: 21 - 28.

Brongniart, A.-T. (1832). Orchidées. In: J. B. G. G. M. Bory, J. B. Fauché, A. Brongniart \& L. A. Chaubard, Expédition scientifique de Morée, Botanique 3 (2). F. G. Levrault, Paris.

Buttler, K. P. (1991). Field guide to orchids of Britain and Europe. Crowood, Swindon.

Cheek, M., Nic Lughadha, E., Kirk, P., Lindon, H., Carretero, J., Looney, B., Douglas, B., Haelewaters, D., Gaya, E., Llewellyn, T., Ainsworth, A. N., Gafforov, Y., Hyde, K., Crous, P., Hughes, M., Walker, B. E., Forzza, R. C., Wong, K. M. \& Niskanen, T. (2020). New scientific discoveries: plants and fungi. Plants, People, Planet 2: $371-388$.

Claessens, J. \& Kleynen, J. (2011). The flower of the European orchid: form and function. Published by the authors, Voerendaal.

Cozzolino, S., D'Emerico, S. \& Widmer, A. (2004). Evidence for reproductive isolate selection in Mediterranean orchids: karyotype differences compensate for the lack of pollinator specificity. Proc. Roy. Soc. London, Ser. B, Biol. Sci. 217: S259 - S262.

, Scopece, G., Roma, L. \& Schlüter, P. M. (2020). Different filtering strategies of genotyping-bysequencing data provide complementary resolutions of species boundaries and relationships in a clade of sexually deceptive orchids. J. Syst. Evol. 58: 133 - 144.

Delforge, P. (2016). Orchidées d'Europe d'Afrique du Nord et $d u$ Proche-Orient (4th edn). Delachaux \& Niestlé, Paris.

D'Emerico, S., Cozzolino, S., Pellegrino, G., Pignone, D. \& Scrugli, A. (2002). Karyotype structure, supernumerary chromosomes and heterochromatin distribution suggest a pathway of karyotype evolution in Dactylorhiza (Orchidaceae). Bot. J. Linn. Soc. 138: $85-91$.

Devey, D. S., Bateman, R. M., Fay, M. F. \& Hawkins, J. A. (2009). Genetic structure and systematic rela- 
tionships within the Ophrys fuciflora aggregate (Orchidinae: Orchidaceae): high diversity in Kent and a wind-induced discontinuity bisecting the Adriatic. Ann. Bot. (Oxford) 104: 483 - 495.

Devos, N., Raspé, O., Jacquemart, A.-L. \& Tyteca, D. (2006b). On the monophyly of Dactylorhiza Necker ex Nevski (Orchidaceae): is Coeloglossum (L.) Hartman a Dactylorhiza? Bot. J. Linn. Soc. 162: 261 269.

, Raspé, O., Oh, S.-H., Tyteca, D. \& Jacquemart, A.-L. (2006a). The evolution of Dactylorhiza (Orchidaceae) allotetraploid complex: insights from nrDNA sequences and cpDNA PCR-RFLP data. Molec. Phylogenet. Evol. 38: 767 - 778.

Dufrene, M., Gathoye, J.-L. \& Tyteca, D. (1991). Biostatistical studies on western European Dactylorhiza (Orchidaceae) — the D. maculata group. Pl. Syst. Evol. 175: 55 - 72.

Eccarius, W. (2016). Die Orchideengattung Dactylorhiza. Published by the author, Eisenach.

Fernandes, F. M., Pineiro Carvalho, M. A. A. \& Aguilar, A. F. (2005). Pollination of Madeiran indigenous orchids. In: Biodiversity and ecology, pp. $25-6$. Proceedings of the $2^{\text {nd }}$ Symposium of Islands Ecosystems.

Foelsche, W. \& Cord-Landwehr, K. (2012). Dactylorhiza cyrnea und die Taxa der Gattung Dactylorhiza auf Korsica. J. Eur. Orch. 44: 167 - 198.

Gölz, P. \& Reinhard, H. R. (1997). Über der Gattung Dactylorhiza - neue Erkenntnisse und neue Fragen. J. Eur. Orch. 29: 585 - 640.

Gower, J. C. (1966). Some distance properties of latent root and vector methods used in multivariate analysis. Biometrika 52: 325 - 338.

(1971). A general coefficient of similarity and some of its properties. Biometrics 27: $857-872$.

(1985). Measures of similarity, dissimilarity and distance. In: Encyclopedia of Statistical Sciences 5: 397 405. Wiley, New York.

\& Legendre, P. (1986). Metric and Euclidean properties of dissimilarity coefficients. J. Classific. 3: $5-48$.

\& Ross, G. J. S. (1969). Minimum spanning trees and single linkage cluster analysis. J. Roy. Statist. Soc. C 18: $54-64$.

Grünanger, P. (ed.) (2016). Orchidee d'Italia (2nd edn). GIROS, Il Castello.

Hagerup, O. (1944). On fertilisation, polyploidy and haploidy in Orchis maculata L. sens. lat. Dansk Bot. Ark. 11: 1 - 25.

Hedrén, M. (2005). Artbildning och slätskap inom orkidésläktet handnycklar Dactylorhiza. Svensk Bot. Tidskr. 99: 70 - 93.
(2021). Spatial genetic structure in the Madeiran endemic Dactylorhiza foliosa (Orchidaceae). Pl. Syst. Evol. (in press).

, Fay, M. \& Chase, M. W. (2001). Amplified fragment length polymorphisms (AFLP) reveal details of polyploid evolution in Dactylorhiza (Orchidaceae). Amer. J. Bot. 88: 1868 - 1880.

Nordström, S., Hovmalm, H. A. P., Pedersen, H. A. \& Hansson, S. (2007). Patterns of polyploidy evolution in Greek marsh orchids (Dactylorhiza; Orchidaceae) as revealed by allozymes, AFLPs, and plastid DNA data. Amer. J. Bot. 94: 1205 - 1218.

, Nordström, S. \& Ståhlberg, D. (2008). Polyploid evolution and plastid DNA variation in the Dactylorhiza incarnata/maculata complex (Orchidaceae) in Scandinavia. Molec. Ecol. 17: 5075 $-5091$.

Heslop-Harrison, J. (1948). Field studies in Orchis L., 1. The structure of dactylorchid populations on certain islands in the Inner and Outer Hebrides. Trans. Ev Proc. Bot. Soc. Edinburgh 35: 26 - 66.

(1951). A comparison of some Swedish and British forms of Orchis maculata L. sens. lat. Dansk. Bot. Ark. 11: 1-25.

(1954). A synopsis of the dactylorchids of the British Isles. Ber. Geobot. Forsch. Rübel 1953: 53 - 82.

(1957). Dactylorchis maculata subsp. rhoumensis (H.Harrison f.) H.Harrison f., comb. nov. Watsonia 4: 48 .

(1968). Genetic system and ecological habit as factors in dactylorchid variation. Jahresber. Naturwiss. Vereins Wuppertal 21+22: 20 - 27.

Inda, L. A., Pimental, M. \& Chase M. W. (2012). Phylogenetics of tribe Orchideae (Orchidaceae: Orchidoideae): based on combined DNA matrices: inferences regarding timing of diversification and evolution of pollination syndromes. Ann. Bot. (Oxford) 110: 71 - 90.

Kreutz, C. A. J. (1998). Die Orchideen der Türkei. Published by the author, Landgraaf.

(2004). Kompendium der Europäischen Orchideen. Published by the author, Landgraaf.

Kristinsson, H. G. (2010). A guide to the flowering plants and ferns of Iceland (3rd edn). Mál \& Menning, Reykjavik.

Kühn, R., Pedersen, H. A. \& Cribb, P. (2019). Field guide to the orchids of Europe and the Mediterranean. Royal Botanic Gardens, Kew.

Landwehr, J. (1977). Wilde Orchideeёn van Europa. Published by the author, Amsterdam.

Mazzola, P., Grisafi, F. \& Romano, S. (1981). Numeri cromosomici per la flora italiana: 850 - 859. Inform. Bot. Ital. 14: 919 - 928. 
Nelson, E. (1976). Monographie und Ikonographie der Orchidaceen-Gattung, III. Dactylorhiza. Published by the author, Zürich.

Nevski, S. (1935). Flora of the URSS, Vol. 4. Komarov Botanical Institute, Leningrad.

Paun, O., Bateman, R. M., Fay, M. F., Hedrén, M., Civeyrel, L. \& Chase, M. W. (2010). Stable epigenetic effects impact evolution and adaptation in allopolyploid orchids. Molec. Biol. Evol. 27: 2465 2473 .

, Luna, J. A., Moat, J., Fay, M. F. \& Chase, M. W. (2011). Gene expression alteration and ecological divergence in sibling allopolyploids of Dactylorhiza (Orchidaceae). BMC Evol. Biol. 11: 113 [14 pp.].

, Turner, B., Trucchi, E., Munzinger, J., Chase, M. W. \& Samuel, R. (2016). Processes driving the adaptive radiation of a tropical tree (Diospyros, Ebenaceae) in New Caledonia, a biodiversity hotspot. Syst. Biol. 65: 212 - 227.

Payne, R. W., Harding, S. A., Murray, D. A., Souter, D. M., Baird, D. B., Glaser, A. I., Welham, S. J., Gilmour, A. R., Thompson, R. \& Webster, R. (eds) (2011). Genstat v14. VSN International, Hemel Hempstead.

Pedersen, H. A. (1998). Species concept and guidelines for infraspecific taxonomic ranking in Dactylorhiza (Orchidaceae). Nord. J. Bot. 18: 289 310.

Pillon, Y., Fay, M. F., Hedrén, M., Bateman, R. M., Devey, D., Shipunov, A., van Der Bank, M. \& Chase, M. W. (2007). Insights into the evolution and biogeography of Western European species complexes in Dactylorhiza (Orchidaceae). Taxon 56: 1185 - 1208.

Shipunov, A. B. \& Chase, M. W. (2006). Species diversity versus phylogenetic diversity: a practical study in the taxonomically difficult genus Dactylorhiza (Orchidaceae). Biol. Conserv. 129: 4 - 13.

Rubin, B. E., Ree, R. H. \& Moreau, C. S. (2012). Inferring phylogenies from RAD sequence data. PLoS One 7: e33394.

Senghas, K. (1968). Taxonomische Ubersicht der Gattung Dactylorhiza Necker ex Nevski. Jahresber. Naturwiss. Vereins Wuppertal 21 - 22: 32 - 67.

Soó, R. de. (1960). Synopsis generis Dactylorhiza (Dactylorchis). Ann. Univ. Sci. Budapest Rolando Eötvos, Sect. Biol. 3: 335 - 357.

(1962). Nomina Nova Generis Dactylorhiza. Published by the author, Budapest.
(1980). Dactylorhiza Necker ex Nevski. In: T. G. Tutin, V. H. Heywood, N. A. Burgess, D. M. Moore, D. H. Valentine, S. M. Walters \& D. A. Webb (eds), Flora Europaea 5: 333 - 337. Cambridge University Press, Cambridge.

Sramkó, G., Paun, O., Brandrud, M. K., Laczko, L., Molnár, A. V. \& Bateman, R. M. (2019). Iterative allogamy-autogamy transitions drive actual and incipient speciation during the ongoing evolutionary radiation within the orchid genus Epipactis (Orchidaceae). Ann. Bot. (Oxford) 124: 481 - 497.

Stace, C. A., Preston, C. D. \& Pearman, D. A. (2015). Hybrid flora of the British Isles. BSBI, Bristol.

Stahlberg, D. (2007). Systematics, phylogeography and polyploid evolution in the Dactylorhiza maculata complex (Orchidaceae). Doctoral thesis, Lund University, Lund.

(2009). Habitat differentiation, hybridization and gene flow patterns in mixed populations of diploid and autotetraploid Dactylorhiza maculata s.l. (Orchidaceae). Evol. Ecol. 23: 295 - 328.

\& Hedrén, M. (2008). Systematics and phylogeography of the Dactylorhiza maculata complex (Orchidaceae) in Scandinavia: insights from cytological, morphological and molecular data. $\mathrm{Pl}$. Syst. Evol. 273: 107 - 132.

\& _ (2010). Evolutionary history of the Dactylorhiza maculata polyploid complex (Orchidaceae). Biol. J. Linn. Soc. 101: 503 - 525.

Sundermann, H. (1975). Europäische und mediterrane Orchideen: eine Bestimmungsflora $\left(2^{\text {nd }} \mathrm{edn}\right)$. Schmersow, Hildesheim.

(1980). Europäische und mediterrane Orchideen: eine Bestimmungsflora (3rd edn). Schmersow, Hildesheim.

Tang, Y., Yukawa, T., Bateman, R. M., Jiang, H. \& Peng, H. (2015). Phylogeny and classification the East Asian Amitostigma alliance (Orchidaceae: Orchideae) based on six DNA markers. BMC Evol. Biol. 15: e96 [32 pp.]

Todaro, A. (1842). Orchideae Siculae sive enumerato orchidearum in Sicilia hucusque detectarum, p. 57. Panormi (Palermo).

Trávníček, P., Jersáková, J., Kubátová, B., Krejčíková, J., Bateman, R. M. \& 22 co-authors (2012). Minority cytotypes in European populations of the Gymnadenia conopsea complex (Orchidaceae) greatly increase intraspecific and intrapopulation diversity. Ann. Bot. (Oxford) 110: 977 - 986 . 
Tyteca, D. \& Dufrene, M. (1993). On the use of distances in the taxonomic study of critical plant groups: case studies of western European Orchidaceae. Ann. Bot. (Oxford) 71: 257 - 277.

\& Gathoye, J.-L. (1989). Contribution a l'étude biostatistique des Dactylorhiza d'Europe occidentale. Mém. Soc. Roy. Bot. Belgique 11: 43 - 64.

Vermeulen, P. (1947). Studies on dactylorchids. Schotanus \& Jens, Utrecht.

(1968). Dactylorchis maculata und ihre formen. Jahresber. Naturwiss. Vereins Wuppertal 21 - 22: 68 - 76.

(1977). Orchideeën, systematisch ingedeeld. In: J. Landwehr (ed.), Wilde orchideeёn van Europa, pp. 551 - 557. VBNN, Amsterdam.
(1978). Dactylorhiza foliosa (Vermeulen) Soó. Orchideeёn 40: 29 - 30.

Vöth, W. (1978). Biometrische Untersuchungen an Dactylorhiza maculata s. 1.-Sippen in Niederösterreich (Orchidaceae). Linzer Biol. Beitr. 10: 179 - 215.

(1999). Lebensgeschichte und Bestäuber der Orchideen am Beispiel von Niederösterreich. Stapfia 65, Biologiezentrum, Oberösterreichisches Landesmuseum, Linz.

\section{Publisher's Note}

Springer Nature remains neutral with regard to jurisdictional claims in published maps and institutional affiliations. 